\title{
Juan García de Miranda: Pinturas religiosas en conjuntos madrileños (I)
}

\author{
TERESA JIMÉnEZ PRIEGo
}

Ofrecemos parte del extenso y profundo estudio elaborado en torno a Juan Garcia de Miranda y su Escuela. En él, primero se nos exigió el esfuerzo de compendiar toda su obra, relaciones e interinfluencias entre sí, con sus coetáneos y artistas extranjeros, para terminar desmembrándolo en diversos artículos y algunos pequeños libros, tales como la producción en torno a Alcalá, Guadalupe o al paisaje; el catálogo de sus obras y bibliografía correspondiente, la actividad en Palacio - tan interesante para el conocimiento de nuestro patrimonio artístico-, etc.

En el presente estudio hemos incluído las obras de este Pintor de Cámara que están relacionadas con entidades madrileñas, y su temática es de carácter religioso. Por no tratarse, en general, de conjuntos amplios, da lugar a una fragmentación de contenidos.

Si bien cada aspecto tiene gran importancia para conocer nuestro poco estudiado siglo XVIII, debemos destacar el referido a la Vida de santa Teresa y a la Inmaculada, por el especial modo de estar representado o la peculiaridades de las escenas o iconografía preferida.

\section{SERIE DE LA VIDA DE SANTA TERESA DE JESÚS (H. 1730-1735)}

La serie de lienzos dedicados a la vida de Santa Teresa debió estar integrada por un número mayor de pinturas, pero desgraciadamente, como otras muchas, solamente nos ha llegado fragmentada y dispersa. Uno de ellos, la Educación de Santa Teresa, se conserva actualmente en el Museo del Prado de Madrid; otro, el de Santa Teresa y su hermano Rodrigo intentando construir ermitas, se encuentra en la Capitanía General de La Coruña; un tercero, Santa Teresa llorando ante la Virgen por la muerte de su madre, fue lamentablemente destruido en 1934, y, un último 
cuadro, conservado en el Monasterio de Carmelitas Descalzas de Alba de Tormes (Salamanca), es el titulado Escena de la vida de Santa Teresa.

La fecha de realización debe situarse muy próxima a la del conjunto de San Diego de Alcalá por las similitudes estilísticas que ofrecen con aquellas obras y porque, a partir de 1734, debido al luctuoso incendio del Alcázar Real, la labor de Miranda se centró casi exclusivamente en la restauración y encargos de Palacio. Pérez Sánchez, en su libro Pintura barroca en España 1600-1750, data la serie hacia $1735^{1}$.

La identificación de estos lienzos, como referentes a la vida de Santa Teresa, no ha sido siempre clara y evidente, como veremos más adelante.

La autoría de Juan García de Miranda en esas obras parece segura, a pesar de no tener firma, dado que sus características estilísticas coinciden con las del artista madrileño.

Su procedencia no la conocemos, mas podrían haberse pintado para el convento carmelitano de San Hermenegildo de Madrid, hoy parroquia de San José. A esta localización nos induce la mayor relevancia del monasterio, así como el elevado número de lienzos con este tema, que aquí se custodiaron. Sabemos que en este convento se reunió una colección de más de 240 cuadros, ponderada por Ponz, Mengs y formada por la diligencia de Fray Antonio de San Joaquín Flores. «Se sabe que en 1814 se les entregaron a los frailes, procedentes del depósito del Rosario, treinta y ocho cuadros, de todos los tamaños, representando la vida de Santa Teresa y San Juan de la Cruz,... y en octubre del mismo año, previa solicitud del convento, otras varias pinturas existentes en la Academia de San Fernando» ${ }^{2}$. En apoyo de esta tesis abogan los inventarios de los cuadros procedentes de los conventos suprimidos de Madrid ${ }^{3}$, los datos de Ponz ${ }^{4}$, Cruzada y otros que nos citan la existencia de diferentes lienzos de Santa Teresa, sin especificarnos el tema concreto representado.

\footnotetext{
1 Pérez Sánchez, Alfonso Emilio, Pintura barroca en España. 1600-1750. Madrid, 1992, pág. 410.

POLEntinos, Conde de, «El convento de San Hermenegildo, de Madrid», B.S.E.E., 1933, año XLI, primer trimestre, marzo, pág. 39.

Archivo General de Simancas, Sección de Gracia y Justicia. Leg. 1247; Rincón, Wifredo, "Un manuscrito con inventarios artísticos de conventos madrileños en 1814", Academia. Boletín de la Real Academia de Bellas Artes de San Fernando, 1985, núm. 60, págs. 332-333; ANTIGÜEDAD del Castillo-Olivares, María Dolores, José Bonaparte y el patrimonio artístico de los conventos madrileños, Madrid, 1987, Apéndices.

4 Viaje de España. Madrid, 1793, t. V, sexta división, números 27-37, págs. 154-158.
} 
Gaya Nuño, en su artículo sobre el «Museo Nacional de la Trinidad» 5 , cita, en el apartado de las obras recogidas de los diferentes monasterios y conventos, cuatro obras de Juan García de Miranda. Tres de ellas podríamos clasificarlas en torno a la temática teresiana. A su vez éstas son también enumeradas por Cruzada ${ }^{6}$.

La identificación que hacen estos autores de dichas representaciones no es correcta ni clara, aunque sí puede ser indicativa.

El cuadro catalogado con el núm. 1.052, lo titula Gaya Nuño Educación de una Virgen y Cruzada Educación de una santa o una reina. El lienzo correspondiente al núm. 302 del Catálogo de la Trinidad lo titulan Santos y ángeles construyendo un pozo, y al núm. 1.055 Santa llorando a los pies de la Virgen. La única obra de la serie que no aparece registrada en los inventarios del Museo de la Trinidad es la Escena de la vida de Santa Teresa.

Los cuatro lienzos tienen similares medidas $(160 \times 225 \mathrm{~cm}$.) y, a pesar de nuestras dudas e interrogantes sin respuesta, podemos coincidir, en esta ocasión, con Carlos Trujillo García ${ }^{7}$ en que la temática de estas obras se refiere a la infancia y juventud de Santa Teresa de Jesús. Y en esto radicaría uno de los mayores atractivos e importancia de estas creaciones.

En los tratados de Iconografía - Réau, Mâle, Cahier, Lexikon der Christlichen Ikonographie, Bibliotheca Sanctorum, ...- se ocupan de las escenas de la vida de la Santa con mayor resonancia, tales como la Transverberación (tan gustada en la época barroca por lo que tiene de efectismo y teatralidad), su definición o proclamación como doctora de la iglesia (cuya inspiración divina se simboliza en una paloma), como escritora mística, etc.

En cambio la infancia y primeros años de su juventud quedan más olvidados. Se recuerdan y comentan literariamente sus gestas de construir ermitas, su fuga a tierras de moros en busca del martirio, ... mas sin que apenas éstas salten a los lienzos. Sólo Domingo Echevarría Chavarito ${ }^{8}$,

\footnotetext{
Gaya Nuño, Juan Antonio, «El Museo Nacional de la Trinidad», B.S.E.E., 1947, págs. 19-77.

Cruzada VILlaAmil, Gregorio, Catálogo provisional historial y razonado del Museo Nacional de Pinturas. Madrid, 1865, págs. 84-85.

7 Trujlllo García, Carlos, "Juan García de Miranda. Dos series de sus lienzos en el Museo del Prado». Boletín del Museo del Prado, 1984, II, 4, págs. 24-26.

8 Pintó una serie de cinco lienzos, de tema teresiano, entre 1712 y 1715 , destinados al convento de Carmelitas Descalzas de los Mártires, en Granada, custodiados actuaimente en el Museo Provincial de Bellas Artes. Chavarito se inspira en los grabados de Collaert y refleja la influencia italiana, pues precisamente al regreso de un viaje de Italia es cuando él recibe este encargo.
} 
pintor granadino de la segunda mitad del siglo XVII y primera mitad del siguiente gusta de estos motivos. Por lo que tienen de ternura e inocencia sintonizaban con el espíritu barroco andaluz. El nos plasmó «la huída de Teresa niña con su hermano Rodrigo a tierras de moros» y su «entrada en el convento» en edad casi adolescente. Con estos lienzos y otras obras, que hemos hallado, estableceremos relación al comentar las de Juan García de Miranda.

Estas representaciones, pues, que estudiamos, constituyen una novedad iconográfica que ejemplificará estas facetas y gestos de la Santa.

Sabemos la relación estrecha que existió entre el convento de carmelitas descalzos de San Hermenegildo y los Miranda por los cuatro lienzos que se conservan en la capilla de Santa Teresa, en la iglesia de dicho monasterio, firmados por Pedro Rodríguez de Miranda, representando escenas de la vida de San Elías, así como los lienzos sobre San Pedro habidos en esta iglesia ${ }^{9}$. Es fácil que completase su trabajo con alguna de las obras referidas a la Santa.

Ignoramos igualmente si los restantes nos narrarían otras escenas de la infancia o recogerían momentos «más sublimes". Pero sí es significativo que en los tres atribuidos a Miranda y conservados exista una aparente unidad temática, y precisamente ésta se corresponda con la menos difundida.

Contestados los primeros interrogantes, pasamos al estudio de los lienzos, los cuales nos llevarán a una profundización en la vida y entorno ambiental de la infancia de Santa Teresa.

Desechamos el título dado por Gaya Nuño, de Educación de la Virgen, al primer cuadro que vamos a comentar, porque creemos que en ninguna ocasión se representó a la Virgen así. Recuérdense los lienzos de Alonso Cano y Murillo. Nunca tuvieron esta ambientación ni acompañamiento de figuras como en el que estudiamos. En el catálogo de la exposición «Pintura Española de los siglos XVI al XIX» ${ }^{\text {to }}$ se cataloga este cuadro como la escena de la educación de una santa. Sin embargo, Pérez Sánchez, en el catálogo de la exposición «Madrid hasta 1875: Testimonios de su historia» ${ }^{11}$,

Antonio Calvo CaStellón estudia y comenta ampliamente estos lienzos en Domingo Echevarria Chavarito (1676-1751). Granada. Cuadernos de Arte, 1979, págs. 253 y ss.

9 Polentinos, op. cit., pág. 53.

10 Catálogo de la exposición Pintura española de los siglos XVI al XIX celebrada en la Casa de Colón de las Palmas de Gran Canaria, noviembre-diciembre de 1973, Madrid, 1973, pág. 11.

11 Catálogo de la exposición Madrid hasta 1875: Testimonios de su historia, celebrada en el Museo Municipal de Madrid de diciembre de 1979 a enero-febrero de 1980, Madrid, 1979, pág. 219. 
lo describe como un «lienzo enigmático» que formó serie con otros, hoy dispersos, episodios todos de la vida de una Santa, por ahora no identificada. Podría pensarse en la infancia de Santa Teresa y en su afición a la lectura, junto a su hermano Rodrigo tal como lo cuenta en su Vida y, posteriormente, en su reciente libro Pintura barroca en España 1600-1750, corrobora la identificación de la Santa con Teresa de Ahumada ${ }^{12}$. Carlos Trujillo ${ }^{13}$ reitera esta identificación con Santa Teresa, indicando que se trata de la representación de la Santa rodeada de su hermano y hermanas. Por nuestra parte pensamos que es evidente se trata de la Educación de una Santa. Pero, ¿en qué santa se cumplen estas circunstancias?. En principio tuvimos ciertas reticencias en aceptar la referencia a Santa Teresa. Tras largas lecturas y por determinadas coincidencias, de las que después hablaremos, nos inclinamos a pensar, no sin reservas, pueda tratarse de una escena familiar de las que pudieron sucederse en tiempo y en casa de Santa Teresa. También cabría la tesis de que fuera una escena de la vida de Isabel la Católica adolescente, como prometida del Infante Don Fernando. Con esta educación iniciaba el adiestramiento cultural e integral que inculcaría y despertaría en todos los reinos que después gobernaría. Sabido es que, por parte de ciertos sectores, se está promoviendo la canonización de la Reina Católica, caracterización que vendría dada por el nimbo que orla su cabeza.

Esta "lectura» debemos desecharla -a pesar de la oportunidad del momento-. En tiempo de Santa Teresa no se pensaba en la canonización de la reina ni en el siglo XVIII ni en los ambientes que pudieron influir e inspirar directamente al artista. Tampoco pensaba en esta posibilidad Alejandro Pidal y Mon al escribir su Doña Isabel y Santa Teresa, en época actual (Madrid, 1913), opúsculo en que hace un estudio paralelo entre la reina y la santa, así como entre sus diversas actuaciones.

Excluida esta posibilidad, vamos a estudiar las coincidencias en espíritu, circunstancias determinantes - arquitectura, vestuario, etc.- de la época de Santa Teresa, santa de la que existen mayores indicios de que pueda ser la representada.

Sabemos que Santa Teresa nace el 28 de marzo de 1515. Es hija del segundo ${ }^{14}$ matrimonio de D. Alonso de Cepeda con Doña Beatriz de Ahumada. Es el tercer fruto de este enlace y nace cuatro años después de

\footnotetext{
12 Pérez Sánchez, Alfonso Emilio, op. cit., 1992, pág. 410.

13 Trujillo Carlos, op. cit, págs. 24-25.

14 Su primera esposa fue Doña Catalina de Pena, de quien tuvo dos hijos - María y Juan-. El segundo desposorio tuvo lugar el 14 de noviembre de 1509 .
} 
su hermano Rodrigo, al que tanto distinguirá con su amistad y cariño, y con el que estará especialmente unida en sus juegos y vida, como ella misma nos comenta. En plena adolescencia queda huérfana de madre ${ }^{15}$.

El lugar feliz de su nacimiento parece ser no la misma Avila, sino la riente aldea de Gotarrendura, cuatro leguas al norte de Avila, donde la familia Ahumada tenía sus grandes posesiones y sus padres se retiraban a invernar, según la costumbre de esa región. "Su casa era la mansión hidalga de la ciudad,... mas no podemos señalar allí su alcoba natalicia porque estaba en Gotarrendura, y su memoria ha desaparecido por completo" ${ }^{16}$.

Su hogar en Avila fue la antigua Casa de la Moneda, una de las intervenidas por la reina Isabel la Católica y comprada por Don Alonso de Cepeda, padre de la santa, en su primer matrimonio. Sus padres eran nobles hijosdalgo, según el testimonio unánime de los testigos que declararon en los procesos de su canonización, y a tal linaje correspondía el escudo de armas de la portada de su vivienda.

La casa de Avila hacía esquina entre la calle de Santa Escolástica y la calle de la Dama ${ }^{17}$. Por los escritos de la santa sabemos que dicha casa tenía un corral con un pozo -extremo que es confirmado por "una carta de troque e cambio del 28 de mayo de $1523{ }^{18}$ por la que Don Alonso cede a Don Juan de Bracamonte «un pedaço de corral de las casas prencipales...», y recibe "un corralejo con un pozo...».

Doña Beatriz, a pesar de su corta edad, parecía una persona mayor. Su educación hogareña se había forjado bajo la influencia renovadora de la reina Doña Isabel. Había crecido recatada y discreta, y una dulcísima gravedad teñía su semblante y llenaba de encantos su extremada hermosura. Este retrato coincide con su representación en el lienzo de Juan García de Miranda. Su misma hija la calificó de «harta hermosura» ${ }^{19}$, de rasgos finos, casi infantiles a la vez que severos, "muy apacible y de harto entendimiento". Juntaba a su educación hacendosa una discreta cultura. Era muy dada a leer, a veces en exceso. Las leyendas devotas y populares tenían en su boca una unción inimitable. A los hijos inculcaba la doctrina cristiana y las prácticas devotas con cariñosa veneración y su voz

Doña Beatriz muere, después de efectuado su testamento, el 24 de noviembre de 1528.

16 P. EFRÉn de la MAdRe de Dios, en la Introducción a la Obras de Santa Teresa, titulada "Tiempo y vida de Santa Teresa», Madrid, 1951, pág. 212, n. 4

lbidem., pág. 117.

lbidem, pág. 177, n. 55.

19 Vida, I, 3. 
insinuante pegaba sus propios sentimientos y hacía inolvidables sus palabras ${ }^{20}$. La dulzura de Doña Beatriz se vio complementada por la severidad y la gravedad caballerosa de Don Alonso. El padre imponía rectitud, fasto y cierta altanería de formas; Doña Beatriz, sencillez, recato, cordialidad. En esa mezcla de cualidades iba a crecer Teresa de Cepeda y Ahumada. Desde los primeros encuentros llegarían muy a su alma el pundonor, la verdad y la esplendidez.

La misma Doña Beatriz fue probablemente la preceptora de la niña Teresa, enseñándole a leer y escribir; ella misma le inculcaría austeridad de costumbres, especialmente en el comer y en el holgar, porque los excesos envilecen el natural y enrudecen el entendimiento. Las horas más bellas de la vida familiar eran quizás aquellas en que se celebraba la escuela hogar. Se rezaba en común y se leían libros en alta voz, que luego comentaban los mayores. Se preferían las hazañas españolas contra los moros, las maravillas del nuevo mundo descubierto por Colón, las proezas de nuestros héroes, las tradiciones avilesas.

Una idea de la indumentaria de Don Alonso nos la pueden dar los retratos de Colón, Luis Vives y Don Fernando el Católico y su representación en el lienzo del monasterio de Alba. Doña Beatriz se ataviaría con los vestidos elegantes de su tiempo ${ }^{21}$. Se usaba por separado la saya o basquiña y el corpiño, de la misma tela, menos las mangas. El gran escote del corpiño se cubría con gonillas de finos pliegues, que se ceñían al cuello con una ancha cinta labrada, a manera de golilla estrecha. Las mangas solían ser largas, estrechas y rizadas o labradas, y excepcionalmente acuchilladas. Los adornos femeninos se prodigaban: soberbias cadenas de oro al cuello, anillos en los dedos, manillas en los brazos, arracadas o pinjantes en las orejas y al pecho una cruz, todo del mismo metal. El calzado de pies y piernas eran chapines altos y calzas coloradas. Los cabellos iban recogidos con una cofia - bellos peinados. A la cintura llevaban colgando una poma de esencias olorosas, las vistosas cuentas del rosario y un espejo dorado.

Nos hemos detenido en esta descripción por coincidir con el vestuario utilizado por la familia representada en el lienzo que estudiamos. Apenas hemos de hacer notar determinadas excepciones, como las mangas bobas que luce la madre (la supuesta Doña Beatriz) que ocupa la lujosa silla, casi «frailera», presidiendo la escena, o las sobremangas labradas de la joven sentada a la derecha.

20 Ibídem, pág. 188-189.

21 BERNIS, Carmen, Indumentaria española en tiempos de Carlos V, Madrid, 1962. 
No ofrecen menos interés que los vestidos los rincones de la casa donde había de crecer Teresa de Ahumada. Ella, nimbada de inocente alegría, correría por sus alcobas, salones, patios y jardín, perfectamente ambientada en las costumbres de su tiempo como una rosa en un rosal.

Ya conocemos la situación de su casa. En su interior tenía, según parece, unos corredores sobre un patio central. Era muy espaciosa, de habitaciones inmensas, con unos corrales anejos y huerta con pozos y una noria hacia la parte sureste ${ }^{22}$. Las grandes baldosas de barro se cubrían durante el invierno con esterillas de junco o de esparto y con alfombras; durante el verano con hierba fresca y olorosa. La parte superior de las paredes ostentaba cuadros, espejos y tapices, y con frecuencia, sobre el fondo enjalbegado, se hacían pinturas al carbón. El aposento principal de la casa era el estrado. Cubierto el suelo con mullidas alcatifas estaba rodeado de cojines; era el asiento de visitantes y visitados. En Castilla era común desde el tiempo de los moros. Las sillas se reservaban para el señor de la casa. Sentábanse cruzando las piernas y abriendo las rodillas como están los ídolos chinos y aún se sientan los moros. Servían también de asiento los cofres, banquillos y ciertos salientes de mampostería que se cubrian de "vancales e alhombras o cueros o esteras según el tiempo» 23 .

Todas estas costumbres están reflejadas en el Inventario de Don Alonso. En su casa tenía antepuertas de figuras rojo y gualda con su escudo familiar, varios reposteros de combinaciones caprichosas y tablas pintadas para cerrar el aparador. Tenía varias alfombras y paramentos, muchos cojines y almohadas de asiento, algunas arcas y arquetas de uso vario, media docena de sillas rústicas y la mesa en que él comía ${ }^{24}$. Como subrayaremos, el artista se ha ceñido con exactitud a todos los detalles.

Los hidalgos recibían una educación harto complicada. La afectación se consideraba propia de personas cultas. Aquellos modales tan artificiosos harían enojar después muchas veces a Santa Teresa que se ahogaba con tantos cumplidos. Santa Teresa, en medio de este ambiente se distingue por su actitud exquisita. Ha sido famosa su afición al agua y a la limpieza, que inculcaría después a sus monjas. En general, bien fuere en Avila o en

22 EFRÉN DE LA MADRE DE DIOS, op. cit., pág. 200 amplía lo antedicho.

23 Ibidem, pág. 203.

24 Ibidem, págs. 204-205. 
las fincas de Gotarrendura, la vida familiar transcurría en medio de un ambiente de paz, austero, sencillo y señorial ${ }^{25}$.

Quisiéramos ahora recrear nuestra mirada en el cuerpecito encantador de aquella niña singular. Pero nadie se preocupó de recoger estas noticias tan halagadoras. Sólo contamos con algunas muy posteriores. Ella se oyó loar infinidad de veces «de discreta, de santa y de hermosa». Y con ser tan menospreciadora de sí, también ella «creía que era discreta y hermosa» ${ }^{26}$. El retrato de su persona, recogido de sus primeros biógrafos, coincidente con el representado en los lienzos que estudiamos, sería el siguiente: "era de mediana estatura, gruesa más que flaca y en todo bien proporcionada. El cuerpo algo abultado , fornido, todo él muy blanco y limpio, suave y cristalino, que en alguna manera parecía transparente. El rostro no nada común; no se puede decir redondo ni aguileño, los tercios de él iguales; la color de él blanca y encarnada, y especialmente en las mejillas, donde parece se veía la sangre mezclada con la leche. María de San José encargó a Fray Juan de la Miseria le hiciera un retrato del natural para que hubiera un refrendo patente de sus verdaderas cualidades, a pesar de que, a juicio de la misma santa, no había logrado su auténtica belleza.

Paralelamente a este retrato físico podríamos reconstruir el moral, según consta de las relaciones contemporáneas. Tenía una sensibilidad sana y equilibrada, pero delicadísima, propensa a las lágrimas, aun cuando tenía perfecto dominio de sí misma. Nunca se mostró tímida, y era especialmente sensible al cariño. Se distinguía por su condición muy generosa, una incansable actividad, briosa por temperamento y vigor espiritual. Fruto muy notable de estas cualidades lo constituía su irresistible alegría. Su presencia sembraba animación y optimismo. Con esta virtud corría pareja un espíritu fogoso que la llevaba a abrazar lo que entendía convenir. Desde sus primeros años dio muestras de su invencible arrojo. Aún podríamos añadir su orden y habilidad estética, sus aficiones literarias y musicales, a pesar de no cantar muy bien. Pero lo que más levantaba su

25 Tal como nos lo canta Gabriel y Galán en su poema de «El Ama», recogido por Fray Gabriel de Jesús (La Santa de la raza. Vida gráfica de Santa Teresa, Madrid, 1929-1933, pág. 264) como expresión de su tranquilidad, alegría y sosiego:

«La vida era solemne,/ puro y sereno el pensamiento era,/ sosegado el sentir, como las brisas,/ mudo y fuerte el amor, mansas las penas,/ austeros los placeres,/ raigadas las creencias,/ sabroso el pan, reparador el sueño,/ fácil el bien y pura la conciencia./ ¿Qué deseos el alma/ tenía de ser buena,/ y cómo se llenaba de ternura/ cuando Dios le decía que lo era!».

26 EFRÉN DE LA MADRE DE DIOS, op. cit., pág. 215; Crolx, Jean de la, «L'iconographie de Thérèse de lesus", Ephemerides carmeliticae, XXI, 1970, págs. 226-227. 
entusiasmo era la visión de la naturaleza, y aún más la cautivaba la soledad, donde se encontraba a sí misma. Ya desde niña la vemos procurarla para rezar sus devociones, y en sus grandes aflicciones la soledad era todo su consuelo ${ }^{27}$.

El carácter de Teresa, mezclado de expansión y rigor, de intensa piedad y enorme soltura de ánimo, cariñosa en extremo y desprendida hasta emprender una fuga, estaba fraguado en una táctica educativa nada común, que logró conservar el candor de la inocencia a la vez que protegía los más atrevidos ideales. Doña Beatriz quería la felicidad para sus hijos pero también los inclinaba a la vida de la gracia y al seguimiento de las virtudes de los santos, cuya ejemplaridad contemplaban en las frecuentes lecturas familiares o de forma individual, como nos lo reflejan diversas representaciones de todas las épocas. Sabemos cómo Teresa a los siete años ya leía a solas el Flos Sanctorum con un conocimiento nada común.

Puede parecer extensa la explicación ofrecida para mejor entendimiento de la escena y como su más clara interpretación. Pensamos que su importancia lo requería, y que, nada más apto, que lo descrito por especialistas del tema y de la época. Ninguna lconografía recoge la Infancia de la Santa, por lo cual tuvimos que acudir a sus mismos escritos, a los procesos de beatificación y canonización y a las primeras biografías de la Santa, escritas por Ribera ${ }^{28}$, Julián de Avila ${ }^{29}$ y Yepes ${ }^{30}$. Los profundos y detallados estudios del carmelita $P$. Efrén, ya citado, también nos han servido de guía segura.

Juan García de Miranda (fig. 1) ha reflejado el ambiente y costumbres con toda exactitud. La amplitud de las salas, las solería, el ruedo de esteriIla, los amplios cojines para sentarse, los reposteros, el vestuario,... En fin, todo se ha cuidado con esmero, creando un ambiente íntimo y hogareño.

27 De una forma acabada nos la retrata Eduardo MARQUINA, poniendo en boca de San Juan de la Cruz los siguientes versos: "Si un día la perdiera/ y por el mundo, errante, la buscara,/ no sé en qué lengua hubiera/ palabras justas para/ decir cómo es de espíritu y de cara./ Buscándola, no habia/ de llamar a las puertas señoriales;/ por las sendas iria/ que enmarañan zarzales; diría a los pastores y zagales;/ «De la tez es trigueña;/ su frente, luna clara en los sembrados;/ trae como lugareña/ de los labios colgados/ los refranes del pueblo y sus dictados./ Pasó, desconocida/ del próspero y feliz; los sinsabores/ de los dolientes cuida;/ y deja, en los alcores,/ con palabras de sol, rastro de flores./ ¿ La han visto?... De ella aprende/ claridad y despejo la mañana; con voz tranquila enciende,/ con fiebre de amor sana,/ jrespira paz de aldea castellana!...", Antología de poesía sacra española. Selección de Valbuena Prat, Apolo, s.l., 1940, págs. 536-537.

28 La vida de la Madre Teresa de Jesús, Salamanca, 1590.

29 Vida de Santa Teresa, 1604.

3o Vida, virtudes, milagros de la Bienaventurada virgen Teresa de Jesús, Zaragoza, 1606. 


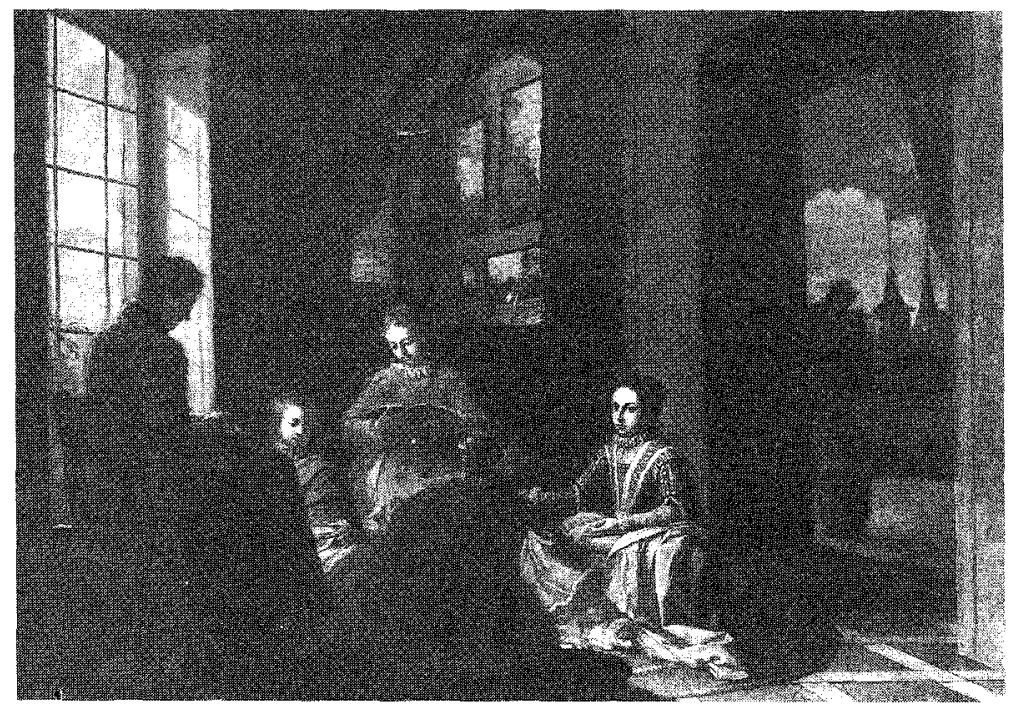

Fig. 1. Juan Garcia de Miranda, "La Educación de Santa Teresa", Museo del Prado.

Esta decoración interior muestra la manera de vivir de la hidalguía acomodada, e incluso Pérez Sánchez ${ }^{31}$ ha llegado a sugerir se tratase de un salón del Buen Retiro, cuyos jardines y torres parecen admirarse al fondo.

La reunión familiar está presidida por Doña Beatriz, que luce los caracteres físicos y morales antedichos. El contraluz en el que está situada ayuda a realzar su figura. Dos de sus hijos, el pequeño Rodrigo y Teresa, leen atentamente, como tantas veces lo harán en soledad, o bien es Teresa la que lee y los demás escuchan. Rodrigo, quien a pesar de ser mayor que la Santa, está representado como más pequeño, parece perderse ensimismado en profundos pensamientos. Otras dos jovencitas, a la derecha, se relacionan entre sí a lá vez que atienden a sus labores de costura y a la lectura. Podrían ser amigas de Teresa, aunque nos inclinamos a pensar encarnan a su hermana mayor, María, y esa prima o parienta próxima con la que la protagonista pronto iba a intimar. Carlos Trujillo en su artículo, ya mencionado, identifica a estas dos jovencitas con las hermanas de Teresa ${ }^{32}$; nosotros, sin embargo, discrepamos en que una de ellas pueda ser su hermana Juana por la diferencia de edad

31 Pérez Sánchez, Alfonso Emilio en el catálogo de la exposición Madrid hasta 1875: Testimonios de su historia, op. cit., pág. 199.

32 TrujtLlo, Carlos, op. cit., pág. 24. 
que existía entre ellas y porque, precisamente, en el mismo año de su alumbramiento fallece su madre.

La escena está situada en un ángulo de honor, abierto y bien iluminado. La severa arquitectura realza el carácter señorial del «rincón». Los objetos domésticos que adornan el alféizar de la ventana fingida y el perrillo que descansa al calor y amor de sus dueñas aproximan la escena a fuer de estas notas realistas-naturalistas.

El paisaje, que se divisa por el gran portón de la derecha, de arquitecturas con torres rematadas en chapiteles de pizarra, lo encontramos más próximo a las construcciones palaciegas de El Escorial, Segovia o Madrid, que a las de Avila. Puede acusar recuerdos de obras de Juan Bautista Martínez del Mazo (El estanque del Buen Retiro, por el chapitel y la frondosidad, o La familia del pintor por la disposición de las figuras y sucesión de planos). Otros quieren ver influencia de Las Hilanderas de Velázquez en los vanos luminosos y la presencia del gato. Creemos que sólo se trata de muestras que nos revelan las múltiples influencias que el autor habitualmente recibía en su prolongada estancia en palacio restaurando y dedicado a la conservación de sus colecciones.

El estudio de la luz, incidiendo en el centro de la escena, subraya la importancia del ambiente espiritual y de unión que domina, a la vez que ilumina los rostros de las figuras principales.

Junto al valor testimonial de modas y costumbres de época, existe también el valor alegórico en el ánfora transparente, imagen de la pureza, el libro en manos de Teresa, que será uno de los atributos de su saber y ciencia, y el perrito como símbolo de la fidelidad. Por otra parte, el espacio tan abierto y las perspectivas lejanas, divisadas por doquier, de forma real o pintada, alude a la categoría social y grandeza de espíritu.

A todos estos aciertos del artista, tan armoniosamente engarzados, se suman los referentes a la composición, colorido, ambientación espacial, iluminación, realismo y observación, reflejados tanto en el vestuario como en la decoración y detalles ornamentales.

La escena presenta una composición circular, lo que conlleva la distribución de las figuras en distintas actitudes: frontal, de perfil, de espaldas, etc, en lo que se muestra muy acertado el pintor. Teresa ocupa el eje frontal del grupo, y su madre y María, la hermana mayor, los puntos extremos más destacados. La figura de la Santa aparece realzada por la aureola de santidad y por la luz que inunda su figura. La «parienta coquetuela» queda más en la penumbra, mientras Rodrigo se acomoda al lado de su hermana andariega y su madre, señalándolas como sus grandes protectoras. 
Debemos llamar la atención sobre el canon utilizado por el artista en las figuras. Es un canon jerárquico, de acuerdo con su importancia y su función, más que con su edad cronológica. Quizás, quiso servirse de él como elemento de caracterización.

El colorido es sumamente agradable, entonado y caliente, y está realzado por una luz tamizada de acuerdo con dicha tonalidad. Los rosas carminosos del vestido de la «parienta coquetuela» se hacen irisados en el jubón y sobrefalda de Santa Teresa y adquieren una tonalidad más cálida e intensa en el atuendo de la madre, semejando calidades aterciopeladas. Los azules celestes del manto de Rodrigo se repiten en la vestimenta de María.

Esta iluminación ambiental refuerza la creación del espacio interior al modo como anteriormente lo hicieran Vermeer (fig. 2), Velázquez, Mazo,...u otros, y refleja el conocimiento que Juan García de Miranda tenía de las obras de éstos artistas, las cuáles, sin duda, contempló en Palacio.

La ambientación espacial la consigue con vanos situados estratégicamente y a través de elementos arquitectónicos que configuran tanto el espacio interior como el exterior. El paisaje y arbolado que se divisa en la gran y rica ventana de la izquierda, se simula en el repostero frontal y se contempla directamente a través de la puerta del ángulo derecho.

Otro aspecto de gran interés, en esta composición, es la importancia prestada a la decoración interior desde el mobiliario, donde destaca la silla

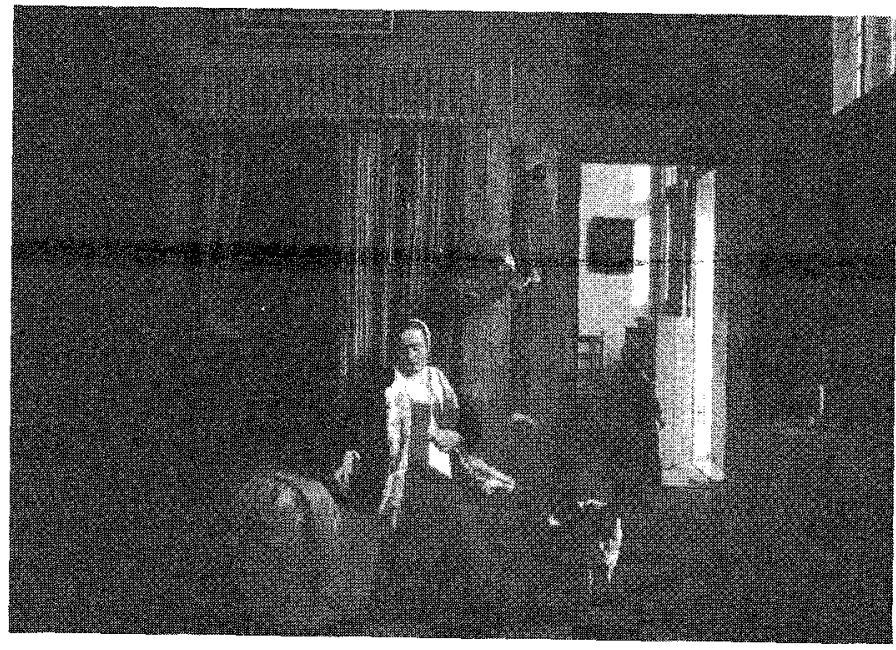

Fig. 2. P. de Hooch: «La madre». Museo de Berlin. 
castellana en que se sienta la madre, hasta la repisa o respostero con su cortina a franjas rojas, blancas y azules. Este pequeño espacio interno del respostero se ornamenta, a su vez, con diversos cuadros ovalados y rectangulares con tema de paisajes, similares a los que conocemos de Pedro Rodríguez de Miranda. En esta misma repisa reposan un vaso y una redoma transparentes, marcados en colores blanquecinos, que reflejan perfectamente las calidades del vidrio. Junto a ellos introduce la variedad de calidad y colorido una cerámica de barro rojo, aprovechando el pintor para mostrar sus habilidades pictóricas en el reflejo rojizo del barro sobre el cristal así como en la distorsión óptica que se genera al contemplar un pequeño fragmento, de un paisaje, a través del vidrio de la botella.

No hemos encontrado representaciones de esta escena sino en dibujos ya de nuestra época, como el de Pripalmary ${ }^{33}$, reproducido unos años después por Jeannine Poitrey suplantando a la verdadera autora. En él se reproduce una escena familiar, presidida por Don Alonso que tiene a Teresa sentada en sus rodillas. La ambientación es igualmente amplia y de aspecto noble.

Con esta formación y atractivo, Teresa sabía granjearse la amistad de todos. El grupo que la rodeaba se movía casi siempre al impulso de ella. Lo formaban varias niñas y algunos de sus hermanos. Sus juegos iban a lo serio. Las lecturas oídas a sus padres los tenían hondamente impresionados y sus diversiones consistian en remedar lo que habían entendido. En la huerta de Don Alonso se los hubiera podido ver más de una vez entretenidos en levantar ermitas con unas piedrecillas y retirarse cada uno como si fueran ermitaños y monjas. Vamos a ver, a continuación, cómo esto es plasmado en el segundo de los lienzos pintados por Juan García de Miranda (fig. 3).

El mejor amigo de Teresa era Rodrigo, cuatro años mayor que ella, pero tan rendido como los demás a sus iniciativas. A los seis años ya leían por su cuenta en aquellos libros de letra gótica, apretada, y contemplaban sus rústicas viñetas que de una vez se lo decian todo. Otras veces Teresa y Rodrigo tomaban el libro que se había leído en familia y se retiraban a releerlo y comentarlo. Teresa hablaba y Rodrigo escuchaba embelesado. El libro podía ser también un Flos Sanctorum que tenía la vida

33 Teresa la grande, Madrid, 1963. 


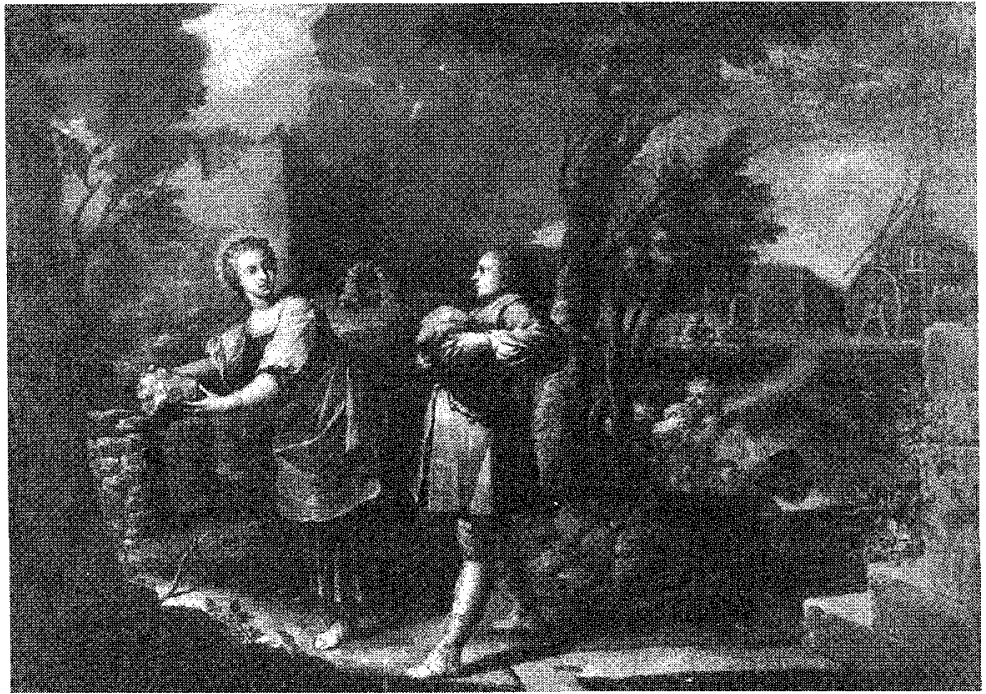

Fig. 3. Juan García de Miranda, "Teresa y su hermano construyendo ermitas", La Coruña: capitania general.

de Cristo y la de muchos santos solitarios, vírgenes, mártires, jovencitos y nobles. Querían seguir la suerte de varios santos buscando para sí el martirio que los llevara a gozar al cielo. Estas lecturas y sus ilustraciones eran un incentivo para su fervor y les marcaba pautas en su obrar.

Respondiendo a estas actitudes de los dos hermanos un grabador del siglo XVIII, Arnoldo van Westerhout, en la primera de las 67 creaciones de su Vita effigiata della serafica vergine $S$. Teresa di Gesu, dedicada a la princesa de Piombino y fechadas en $1716^{34}$, nos los plasma leyendo en un paraje monacal. Mas, en esta ocasión, será Rodrigo el que está sentado con un libro abierto sobre sus rodillas y, junto a él, de pie, Teresa. Al fondo, en el jardín que sirve de escenario, se ven dos pequeñas capillas de paja, aludiendo a lo que cuenta la santa («...Ordenábamos ser ermitaños y en una huerta que había en casa procurábamos como podíamos hacer ermitas, poniendo unas piedrecillas que luego se nos caían, y así no hallábamos remedio en nada para nuestro deseo". Vida, I, 6). Y el P. Francisco Ribera, biógrafo de la santa, dice: "Cuando jugaba con otras niñas, gustaba mucho de hacer monasterios» 35 .

34 BNM ER 1619.

35 La vida de la Madre Teresa de Jesús, Salamanca, 1590, I, I, IV. 
Aunque, con matices algo diferentes, este grabado podría ser el antecedente, del lienzo de Miranda. Este mismo carácter pudo tener la viñeta del Flos Sanctorum, de Fr. Pedro de la Vega, pero en relación con la decisión de Teresa. De forma más cercana en el estilo y en la representación, y, por tanto, como precedente más claro, cabe citar las dos figuraciones gemelas que decoran el camarín alto y la sacristía del convento de carmelitas descalzas de Alba de Tormes, Salamanca. A pesar de las diferencias, sólo ellos son anteriores a la creación que estudiamos.

Las representaciones de Alba de Tormes sintetizan, en dos medios puntos, los motivos más interesantes de la infancia de la Santa. Ambos medios puntos son iguales en sus medidas y figuración, difieren en una inscripción referida a la historia representada, que se lee en el de la sacristía y está ausente en el otro. Estos tres momentos se refieren al de la Huida a tierra de moros (a la derecha), Cuando niña levantaba monasterios en el jardín de su casa (a la izquierda) y su Entrada en el convento de la Encarnación (en el centro). La composición y tipología responden a la caracterización del arte popular suramericano, del que existen obras en el mismo convento salmantino. La escena con los aspirantes a ermitaños tiene algunos elementos diferenciales del resto de las del mismo tema. Las ermitas no se construyen con piedras o paja, sino con madera, y el escenario no corresponde a una huerta con pozo sino a unos jardines de estilo geométrico francés. En general, esta escena resulta floja y con pocos aciertos de dibujo y perspectiva.

Su datación debe situarse con posterioridad a 1677, cuando, al finalizar las obras de ampliación de la iglesia, se inició el ornato de la sacristía y demás dependencias. Por tanto, las pinturas debieron realizarse alrededor de estas fechas.

La del lienzo de Juan García de Miranda, que nos plasma el referido tema de "la construcción de ermitas por Teresa y Rodrigo", es igual al anterior, de la Educación de la Santa, en sus medidas y en las figuras. Nos reproduce en Santa Teresa el mismo tipo humano, correspondiéndose con las descripciones realizadas por sus coetáneos y citadas anteriormente por nosotros. Rodrigo tiene rasgos faciales similares a los de su hermana y una edad superior a ella, como era en realidad. Ambos trabajan en el jardín de su casa en construir las consabidas ermitas o monasterios. Teresa coloca las piedras que su seguidor le acarrea. Unos ángeles alivian su cansancio y cooperan en la tarea transportando también material. Teresa y Rodrigo visten traje de diario y calzan sandalias de tipo romano atadas en la pantorrilla. La niña luce falda azul adornada con cintas, blusa blanca y corpiño rojizo. Ciñe a la cintura, 
como un delantal, una capa de tonos marrones-rojos, agradables. Rodrigo porta una larga casaca, sujeta a la cintura y con mangas, que apenas nos permite ver sus ajustados pantalones semicortos y la camisola que irrumpe por la abertura desabrochada de las mangas y el amplio cuello. Ambos llevan algún distintivo de su nobleza, como pueden ser la pulsera y collar de perlas, en Teresa, y la cadena adornada con piedras que pende de la casaca de Rodrigo. Los rostros de los dos hermanos están pintados con esmero. Es notable su parecido entre sí y con los figurados en el cuadro anterior, como anticipamos. Sus carnaciones, así como el diseño de sus manos, responden a la perfección que suele caracterizar al autor. Su posición es paralela y contrapuesta, con lo que amplían los planos y marcan diferenciadamente el espacio. La compenetración de su mirada es expresión de su íntima unión en sus empeños infantiles.

El colorido responde a la gama caliente y brillante más característica de Juan de Miranda. Si en el vestuario y figuras es notable, acrecienta sus perfecciones y calidades en el paisaje y atmósfera, de forma tan similar a los paisajes de Pedro Rodríguez de Miranda que nos hace pensar en una posible colaboración, en estos detalles, de su discípulo y sobrino. En este lienzo están presentes los celajes azules-verdosos con toques rojizos que también apreciábamos en el cuadro de San Pascual Bailón titulado Santo pastor adorando a un ángel.

La amplitud del jardín, los árboles centenarios que lo surcan, las robustas arquitecturas que lo circundan muestran el carácter noble de la casa a la cual pertenecen.

La composición resulta atrayente por el tema y su resolución. Su esquema de friso le da de un carácter narrativo, descriptivo, sin más intelectualizaciones, a no ser el posibie anuncio de su futura tarea de fundadora. Algunos detalles anecdóticos le prestan nuevo encanto: tales como la pequeñez, espontaneidad y esfuerzo de los angelitos, la noria y su acabada perfección, que alude al riego y a la fecundidad de la huerta, así como a la realidad del escenario, cuyos datos ya subrayamos con antelación. La perspectiva espacial está marcada por los árboles, las arquitecturas y el diferente colorido e intensidad del aire que lo recrea y las nubes que lo cubren. La nota popular y poética del paisaje simula inspirada en el Paisaje con ovejas del lienzo de Murillo Jacob pone las varas ${ }^{36}$ (fig. 4).

36 Dallas, Meadow Museum, cat. 31. 


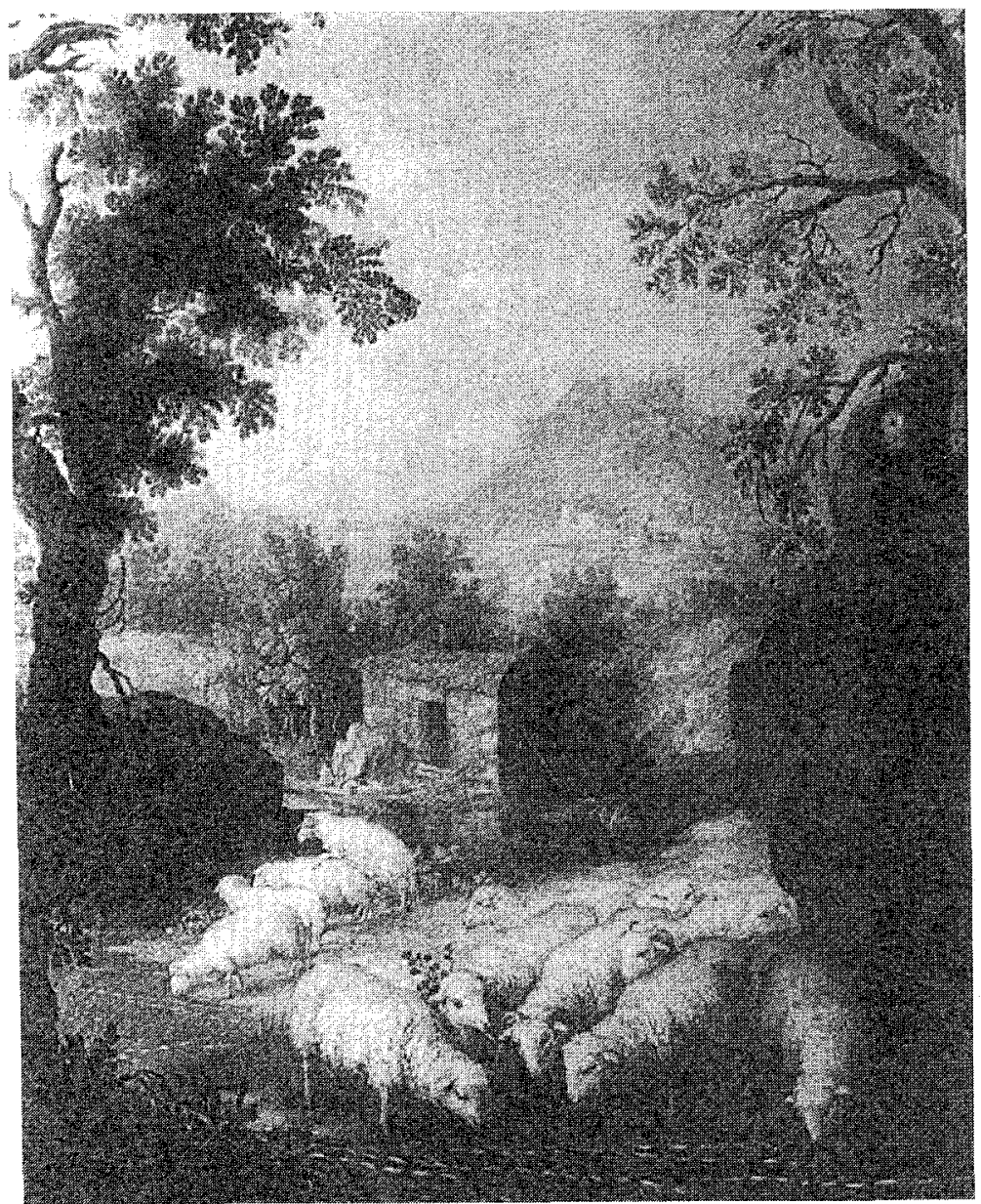

Fig. 4. Murillo, "Jacob pone las varas». Paisaje con ovejas, Dallas, Meadow Museum.

Podemos hoy disfrutar de la contemplación de este lienzo por haberse salvado del incendio que asoló el Palacio de Justicia en marzo de 1914 y en el que perecieron obras de Juan de Miranda, como el de Santas y santos dominicos y franciscanos, depositados ambos en dicho Palacio desde $1881^{37}$.

37 Tormo, Elías, «La Galería de Cuadros del incendiado Palacio de Justicia», B.S.E.E., pág. $166-177$ 
El tema parece no haber tenido continuidad hasta el siglo $\mathrm{xx}$ en que unos sencillos dibujos nos lo recrean de nuevo.

Cuando Teresa tenía trece años y medio, en el otoño de 1528, en un día no marcado en el recuerdo, Doña Beatriz, su madre, moría rodeada de su esposo e hijos. Esta separación fue en extremo sensible para la santa, la cual nos la describió más tarde. "Acuérdome que cuando murió mi madre - nos dice ${ }^{38}$ - quedé yo de edad de doce años ${ }^{39}$, poco menos. Como yo comencé a entender lo que había perdido, afligida fuíme a una imagen de Nuestra Señora y supliquéla fuese mi madre, con muchas lágrimas. Paréceme que, aunque se hizo con simpleza, que me ha valido: porque conocidamente he hallado a esta Virgen soberana en cuanto me he encomendado a Ella» ${ }^{40}$. La tradición dice que esta súplica la hizo Teresa ante la imagen de Nuestra Señora de la Caridad, que actualmente se encuentra en la catedral de Avila. López Anglada ${ }^{41}$ nos describe y plasma este momento en el soneto que titula «Muere doña Beatriz de Ahumada, madre de Santa Teresa, y ésta, de doce años, suplicó a una imagen de Nuestra Señora que fuese su madre».

A esta escena parece debió corresponder el tercero de los lienzos que Cruzada recoge como de Juan García de Miranda. Este óleo, que, por la descripción que nos hace el autor citado ${ }^{42}$, podía titularse Santa Teresa llorando ante la Virgen la muerte de su madre, fue depositado en la Universidad de Oviedo por Real Orden de 18 de abril de 1885, teniendo en el Catálogo de la Trinidad el número 1.055, siendo, al parecer destruido en 1934. Cruzada nos habla de esta representación en los términos siguientes: "A la izquierda sentada sobre un trono de nubes, la Santísima Virgen; a sus pies una santa llorando. A la derecha, y en el fondo de una capilla de una iglesia, un personaje muerto sobre un ataúd, al que alumbran

\footnotetext{
38 Vida, I, 7.

39 No están de acuerdo los diferentes autores ni la misma Santa. El P. EFRÉN DE LA MADRE DE Dıos, en la op. cit., pág. 277 y $n .7$, recoge estos datos.

40 Ribadeneyra, Pedro, op. cit., Madrid, 1761, t. 3, pág. 272.

41 «Ved que cuando la muerte determina/ ceñirnos la garganta, no parece/ sino que hasta la luz se desvanece/ y hasta el cabo del mundo se termina.// Aprieta Dios y apenas se adivina/ hasta dónde ha de ahogarnos. Negra, crece/ la soledad más dura y aparece/ el desgarrón de la primera espina.// Fue cuando tuvo adolescencia el llanto,/ principio la amargura y el espanto/ se inauguraba en una frágil presa.// Y mientras una madre se moría/ apagando a Castilla, otra acudía/ al mayor desconsuelo de Teresa». (pág. 23)

42 Catálogo, pág. 85.
} 
cuatro grandes candelabros». Por el paralelismo y afinidad de detalles que existe entre esta descripción y la creación del artista flamenco, tan insistentemente aludido, nos hace pensar sea el grabado el antecedente del lienzo de Miranda. En efecto, en el grabado $V$ de la serie de Westerhout (fig. 5) esta sencilla súplica de la Santa se interpreta, también, como una aparición de la Virgen, que, sobre una nube, para indicar su procedencia celeste, acoge a Teresa, arrodillada ante ella. En un segundo plano y tras una balaustrada se ve a la madre de la Santa, muerta, en un ataúd y entre dos cirios. Por no haber podido conocer el lienzo nos vemos privados de cualquier otro comentario.

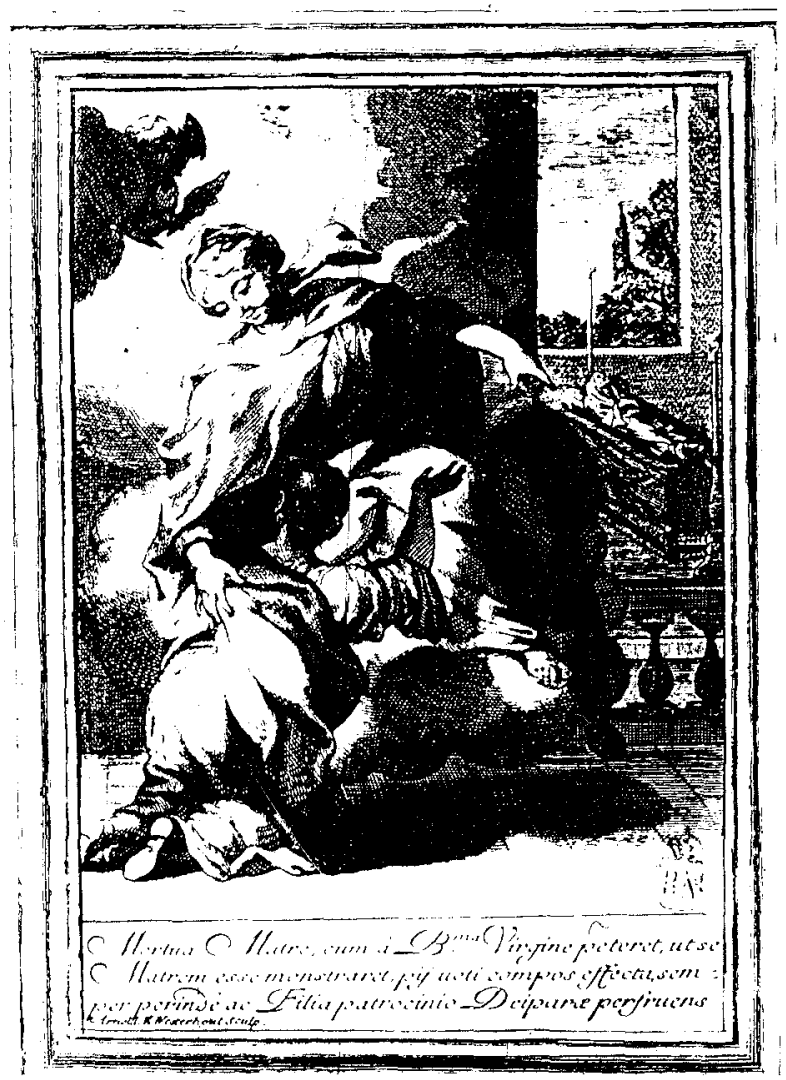

Fig. 5. Santa Teresa llorando ante la Virgen la muerte de su madre. Grabado de Westerhout, s. XVIII. BNM ER 1619 
Este momento, a pesar de su dramatismo y menor atractivo, ha sido bastante repetido en dibujos actuales, como los de la autora ya citada, de Fripalmary y los de María Rosa García ${ }^{43}$.

Comenzó Teresa a aficionarse a los libros de caballería, pasatiempos y otras "vanidades» que fueron «enfriando» su virtud. Frecuentó más asiduamente la amistad con sus primos hermanos y una parienta de costumbres opuestas a la de su hermana María, algo mayor que ella, "de gran honestidad y bondadosa». Procuraba agradar a todos y esto llevó a Teresa a preocuparse por la mejora de su apariencia y semblante.

María y su padre procuraron apartarla de estas compañías y pasatiempos. Pasados tres meses en estos devaneos, Don Alonso condujo a su hija al monasterio de Religiosas Agustinas, de Avila, donde se educaban otras jóvenes «semejantes, aunque no tan ruines en costumbres como yo" - dice la Santa- Su paso al internado tuvo lugar tras el matrimonio de María, acaecido en 1531, so pretexto de que al "quedar sola y sin madre no era bien".

Allí se ganó el amor y la amistad de todas con la misma facilidad con que lo lograra en su ambiente familiar. Con los buenos ejemplos de sus compañeras y principalmente de Doña María de Briceño, que las dirigía, recuperó sus buenos deseos e inclinaciones. Al cabo de año y medio sufrió «una gran enfermedad» y tuvo que volver a la casa de su padre.

Una vez repuesta de sus males manifestó a su padre sus deseos de retirarse a un monasterio. Al no poder obtener el permiso paterno, comenzó a hacer más frecuentes sus visitas al convento de Carmelitas de Avila, el de la Encarnación, donde vivía una gran amiga de ella, Doña Juana Suárez, que siempre habría de acompañarla. Estas visitas levantaban sus ánimos de una manera especial y fueron tan numerosas y su porte tan inconfundible que motivaron que una religiosa, años después, la recordara "cuando venía de seglar algunas veces a este convento, y doy por señas que traía una saya naranjada con unos ribetes de terciopelo negro» ${ }^{44}$.

\footnotetext{
43 Reproducidos en Santa Teresa de Jesús de Sanz Burata, Barcelona, 1967, pág. 22.

44 P. Efrén de la Madre de Dios, op. cit., pág. 317, 253, n. 22 Carta de Da. María Espinel a su Prelado... («Bibl. Mist. Carmelitana», t. 2, pág. 113).
} 
Su entrada en el nuevo estado tiene lugar el 2 de noviembre de 1535, a los 19 años. Parece ser tuvo como maestra de novicias a Doña María de Luna ${ }^{45}$, como priora a Dña. Francisca de Aguilar y a Dña. María Cimbrón, como superiora. Transcurrido el año reglamentario, el 2 de noviembre de 1536, según el ritual al uso, viste el hábito del carmelo.

Desde entonces comenzó a sentir nostalgia de los antiguos solitarios del Yermo, cuya memoria crecería con el tiempo en su corazón, emulando su vida austera y pobre, de infinitas mortificaciones corporales. Los entusiasmos de su noviciado podemos barruntarlos por el arrojo que demostró en su huída a tierra de moros, en la salida de casa de su padre, etc.

A los 22 años, el 3 de noviembre de 1537, emite su Profesión religiosa ante Fray Antonio de Lara, provincial de los Carmelitas, y Doña Francisca del Aguila, priora del convento de la Encarnación (Avila). Cómo pasó su primer año de profesa nos lo comenta al escribir: «La mudanza de la vida y de los manjares me hizo daño a la salud... Comenzáronme a crecer los desmayos y dióme un mal de corazón tan grandísimo que ponía espanto a quien lo veía, y otros muchos males". Como los médicos no encontraban remedio, su padre, obtenidos los permisos oportunos, la condujo hasta Becedas en donde esperaba que otros médicos llegasen a sanarla. Esta penosa salida tuvo lugar en el otoño de 1538. Salió acompañada de su amiga íntima, la religiosa Juana Suárez ${ }^{46}$. Tuvo que permanecer fuera del monasterio un año para su curación. En éste no padeció menos dolores, dado el poco acierto de los remedios que le aplicaron.

Al llegar el 15 de agosto de 1539 Teresa pidió confesarse, lo que impidieron su padre y acompañantes. Aquella misma noche de la fiesta de la Virgen de agosto sufrió un paroxismo y quedó como muerta durante cuatro días. En ellos le administraron el sacramento de la Unción y le hicieron la recomendación del alma, pues la tenian por muerta. Acudieron frailes del convento del Carmen y monjas de su monasterio a estar con ella. En este tiempo «teniánme por tan muerta que hasta la cera me hallé después en los ojos" ${ }^{47}$. A los cuatro días volvió en sí con gran regocijo de todos, especialmente de su padre, quitándole inmediatamente la cera de los ojos. Despertaba como si delirase diciendo cosas peregrinas. "Comenzó a decir, escribe el Padre Ribera, que para que la habían llamado, que estaba en el cielo y había visto el infierno, y que su padre y otra monja, amiga suya,

45 P. Efrén de la Madre de Dios, op. cit., pág. 327.

46 TeResa de Jesús, Vida, op. cit., cap. $4,4$.

47 Ibídem, cap. 5, 9, y P. EFRÉN DE LA MADRE DE DIOS, op. cit., pág. 395. 
llamada Juana Suárez, se habían de salvar por su medio, y que vió también los monasterios que había de fundar y lo que había de hacer en su Orden, y cuántas almas se habian de salvar por ella y que había de morir santa y que su cuerpo antes que lo enterrasen había de estar cubierto con un paño de brocado» ${ }^{48}$. Cuando acabó de recobrar el sentido solicitó confesarse y, acto seguido, recibió la comunión. Esta recuperación del paroxismo no significó su curación, pues quedó todavía con terribles dolores en todos sus miembros y nunca le faltaron en toda su vida amagos de perlesía, especialmente en el brazo izquierdo. Todas estas dolencias las mantuvo aún durante tres años, aunque regresó de nuevo al convento a fines de agosto de 1539, cuando, al parecer, tenía 24 años. La ausencia de estos dolores y fatigas comenzó a aparecer con motivo de la celebración de la festividad de San José, a quien la Santa había tomado como medianero y abogado.

Este cuarto lienzo titulado Escena de la vida de la Santa (fig. 6) representa la muerte aparente de Teresa, ocurrida en su juventud y evocada por ella misma en su Vida ${ }^{49}$. La biografía del Padre Ribera proporciona algunos datos más, que la Santa silencia, como son su estancia en el cielo y su disgusto por el regreso a la tierra.

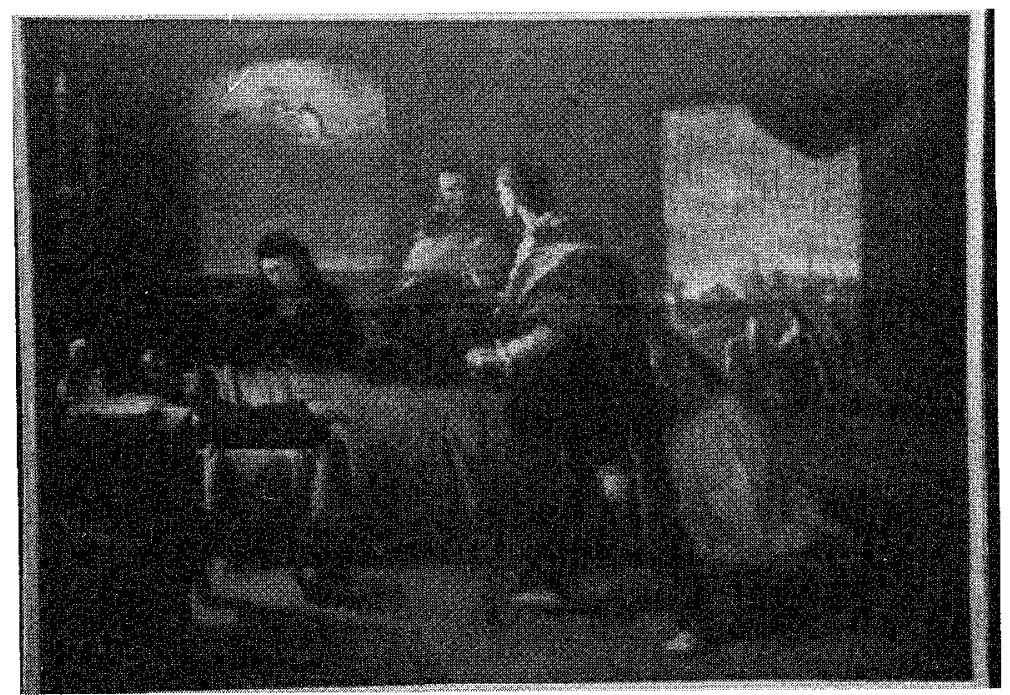

Fig. 6. Juan García Miranda, "El paroxismo». Convento de Carmelitas de Alba de Tormes.

48 P. Efrén de la Madre de Dios, op. cit., págs. 395-396.

49 Vida, cap. V. 
El cuadro, como los anteriores de formato apaisado, presenta una acertada composición de los elementos y una correcta disposición de las figuras.

Los personajes representados son: Santa Teresa yacente en el lecho con los ojos cerrados, y su rostro y manos presentan un color céreo y macilento como si efectivamente estuviese muerta, pintándola incluso rodeada de cirios.

Alrededor de su lecho se sitúa en primer plano su padre, Don Alonso, quien va calzado con sandalias de lazada, viste calzas acuchilladas, camisa con gorguera cuyas mangas van rematadas con encajes, y luce una capa de color rojo ácido, que cruza su cuerpo por la parte delantera para, posteriormente, caer a lo largo de la espalda. Su mano derecha se apoya en un bastón. Las manos están ratadas con una pincelada suelta y el dedo índice de la mano diestra aparece levantado en signo aleccionador, estando además fuertemente iluminado. Su rostro de perfil, muy iluminado, presenta una gran belleza y serenidad, correspondiendo por completo al de un hombre maduro. También es digno de resaltarse el tratamiento de su pelo cano. La postura de sus piernas, un poco forzada, nos recuerda las que aparecen en otras obras de García Miranda como el Asesinato del Padre Torres o San Diego en las Islas Canarias.

A los pies de la cama, arrodillada, se encuentra María, la hermana de Teresa, ataviada con una falda roja anaranjada con numerosos pliegues, que se arremolinan en la parte baja. El cuerpo del vestido, de tonalidad más oscura, próxima al púrpura, contrasta con el color blanco de las mangas de la camisa.

Al otro lado del lecho se sitúan Juana Suárez, religiosa amiga de la Santa, cuyo rostro aparece inundado de sombras oscuras, únicamente matizadas por algunas notas de luz en el ángulo superior derecho del ojo y la frente. Viste hábito carmelita, contrastando su toca negra con el color blanco del rostrillo. El fraile, que se encuentra a su izquierda, viste asimismo hábito carmelita y capucha blanca, y parece ser que fue el encargado de suministrarle la extremaunción. Destaca en su figura la fuerte luminosidad de su frente en contraposición con el resto del rostro.

Esta pintura resulta de gran interés y atractivo por varias razones que analizaremos a continuación. La distribución de los personajes en el espacio pictórico está realizada con gran acierto, concediendo a cada uno de ellos un puesto en correlación con su protagonismo en la escena.

El espacio ha sido perfectamente calculado y estructurado, combinando sabiamente el espacio interior de la habitación, el exterior del paisaje, 
que se divisa a través de la apertura del lado derecho, e incluso llega a introducir de manera bastante acertada el espacio celeste, por medio del vano del lado izquierdo, que simula una especie de ventana o cuadro dentro del propio cuadro.

En el ámbito celestial, donde predominan las entonaciones de colores dorados y cálidos, verdes rojizos y azulados, se encuentra representada la visión de Santa Teresa, quien durante su enfermedad, cree encontrarse ante Dios Padre. Este aparece pintado en la gloria, sentado sobre las nubes, y rayos luminosos dorados circundan su cabeza. La Santa, por su parte, aparece con manto blanco y toca negra, arrodillada en postura reverente a sus pies.

El paisaje exterior recuerda muy de cerca los de la escuela de pintura madrileña del siglo XVII y más concretamente los de Velázquez. Se aprecia una pequeña ciudad amurallada, tal vez se trate de una evocación un poco ficticia o imaginaria de la capital abulense o de los monasterios que la Santa fundaría posteriormente y que contempló en su visión. Destacan dentro de este conjunto urbano varios edificios coronados y rematados en chapiteles de pizarra. Delante de este paisaje y casi en el mismo umbral del vano o puerta se encuentra representado un grupo de cinco monjas con hábitos carmelitas de color pardo, con capas blancas y tocas negras. Presumiblemente, algunas de ellas serían la priora Dña. Francisca del Aguila, que le otorga el habito y acepta su profesión; la superiora Dña. María Cimbrón; su madre maestra de novicias Dña. María de Luna; Isabel del Valle y una de sus mejores confidentes Dña. María de San José.

La amplitud del escenario está conseguida mediante la superposición de planos paralelos tratados con diferente intensidad lumínica y por medio de vanos que permiten la introducción de otras escenas secundarias.

Los muebles y objetos de la habitación se reducen a los mínimos e indispensables. El lecho donde yace la Santa, y, en el lado izquierdo, una mesa de madera castellana donde reposan una redoma de cristal y un plato de loza blanca con decoraciones de azul manganeso. La redoma de cristal presenta muchas similitudes, en su tratamiento pictórico, con la que aparece representada en el lienzo de La educación de Santa Teresa, tanto en la captación de la transparencia del material como en los reflejos y reverberaciones que originan los líquidos contenidos en el recipiente, así como en los toques de pintura de color blanco, que utiliza el artista para conseguir estos efectos. Ante la cama reclama nuestra atención un hisopo de bronce dorado.

Todos estos objetos están tratados con un gran realismo, recreándose el pintor en los detalles, pormenores y cualidades táctiles de los tejidos, 
que manifiestan su carácter observador y su capacidad técnica. Este tratamiento realista y naturalista de los objetos y el ambiente presenta evidentes vinculaciones con los talleres madrileños del siglo XVII. Otro de los elementos en que se manifiesta este aspecto meticuloso, observador y detallista está presente en las baldosas rojizas, de las que se sirve para crear efectos de perspectiva, pero donde además se recrea con esmero es en la representación de sus uniones y en los desperfectos o desgastes ocasionados por el paso del tiempo y el uso cotidiano.

El pintor, siguiendo la tradición propia del barroco, concede gran importancia al lenguaje de los gestos y las miradas, que sirven para enlazar unas figuras con otras y dar unidad a la composición. Aquí podemos apreciarlo con bastante evidencia en los rostros y miradas que entrecruzan Don Alonso y el fraile carmelita, que además aparecen resaltados con una mayor intensidad lumínica. También se refuerza esta comunicación con los gestos de las manos, sobre todo en el dedo índice de la mano derecha de D. Alonso. Algo similar podemos afirmar de Juana Suárez, cuya mirada, nos conduce inevitablemente al rostro de la Santa, o el grupo de las cinco religiosas llorosas y condolidas por la enfermedad de Teresa, cuyos rostros reflejan un sentimiento de dolor y pena, además de la comunicación, a través de la mirada, que se establece entre las dos situadas en el plano más avanzado.

La primera insinuación de que esta obra pudiera deberse a Juan García Miranda fue formulada por Emilia Montaner López ${ }^{50}$, quien, en el comentario de este lienzo, afirmaba: «El modelado de los volúmenes vinculado todavía al tenebrismo y la ordenación de la composición en planos paralelos en profundidad, recuerdan a los maestros madrileños de finales de siglo, más especialmente a Juán García de Miranda (1677-1749)». Posteriormente en el catálogo de la exposición «Pintura barroca en Salamanca. Escuelas españolas», a la hora de catalogarlo lo cita como anónimo madrileño del último tercio del siglo XVII, pero al realizar el comentario de la obra mantiene la tesis anterior escribiendo «Quizá no resulte excesivo relacionar la obra con Juan García de Miranda, quien pintó una serie dedicada a la vida de Santa Teresa probablemente destinada a conventos carmelitas, tres de cuyos ejemplares -semejantes al lienzo de Alba en dimensiones y estilo- ingresaron en el Museo Nacional de la Trinidad, sin que se conozca el lugar de su origen» 51.

50 Montaner López, Emilia, La pintura barroca en Salamanca, 1987, págs. 188-189 y nota 27.

51 MONTANER López, Emilia, La pintura barroca en Salamanca. Escuelas Españolas, catálogo de la exposición celebrada en el Museo Provincial de Salamanca, Salamanca, 1987, pág. 61. También realiza algunas alusiones a esta obra en las páginas 14 y 17 . 
Nosotros compartimos la tesis expuesta por esta investigadora y estimamos, como ella, que puedan atribuirse a Juan García de Miranda por diversos motivos, algunos de los cuáles expondremos a continuación. Una primera coincidencia es la concordancia de formato de los cuatro lienzos, a lo que se suma su correlación temática, siendo probable que la serie se completase con otras escenas de la infancia y juventud así como de su ingreso en el convento y vida posterior.

Otro argumento nos lo proporciona la similitud en las entonaciones del colorido que presenta este cuadro con los otros de la serie, a lo que se añade todo otro conjunto de detalles. Algunos de ellos ya los hemos esbozado en el comentario de la pintura, como es el parecido entre la redoma y su tratamiento pictórico con la que aparece en el lienzo de La educación de Santa Teresa; la postura de las piernas de Don Alonso, repetida en varios personajes de los cuadros de Juan García de Miranda; la cortina que pende en el ángulo superior de la puerta, que también reitera el del ya antes mencionado cuadro de la educación; el paisaje de notas madrileñas, que es semejante tanto en este lienzo como en el de San Isidro o la Educación de Santa Teresa, etc.

Esta escena fue recreada con anterioridad por el grabador Collaert (fig. 7) con el cua! este lienzo presenta ciertas concomitancias. Erróneamente algunos, como Antonio Calvo Castellón ${ }^{52}$, han interpretado este grabado como la muerte de Santa Teresa, mas representa el paroxismo y no la muerte. En confirmación de la identificación del tema podemos añadir que Westerhout reconoce este momento y nos graba también la escena en que Teresa es curada de esta enfermedad por la intercesión de San José ${ }^{53}$. Es disculpable la confusión de ambos momentos por las notas comunes que conllevan.

A pesar de lo antecedentes, aún nos queda un interrogante sin resolver, al que todavía no hemos encontrado respuesta y es el de cómo ha podido llegar este cuadro al convento de las Carmelitas Descalzas de Alba de Tormes. Posiblemente llegase procedente del convento madrileño de San Hermenegildo, de cuya serie se desglosase en uno de los múltiples avatares que sus obras artísticas sufrieron a lo largo de los tiempos. Estos préstamos y donaciones quedan muy de manifiesto al ver la documentación de diversos conventos suprimidos, custodiados en diversos archivos (Academia, Simancas, particulares, etc.).

52 Calvo Castellón, Antonio, op. cit, págs. 266, 272 y 324 (nota 81), fig. 18.

53 EESTERHOUT, grabado. BNM ER 1.619. 


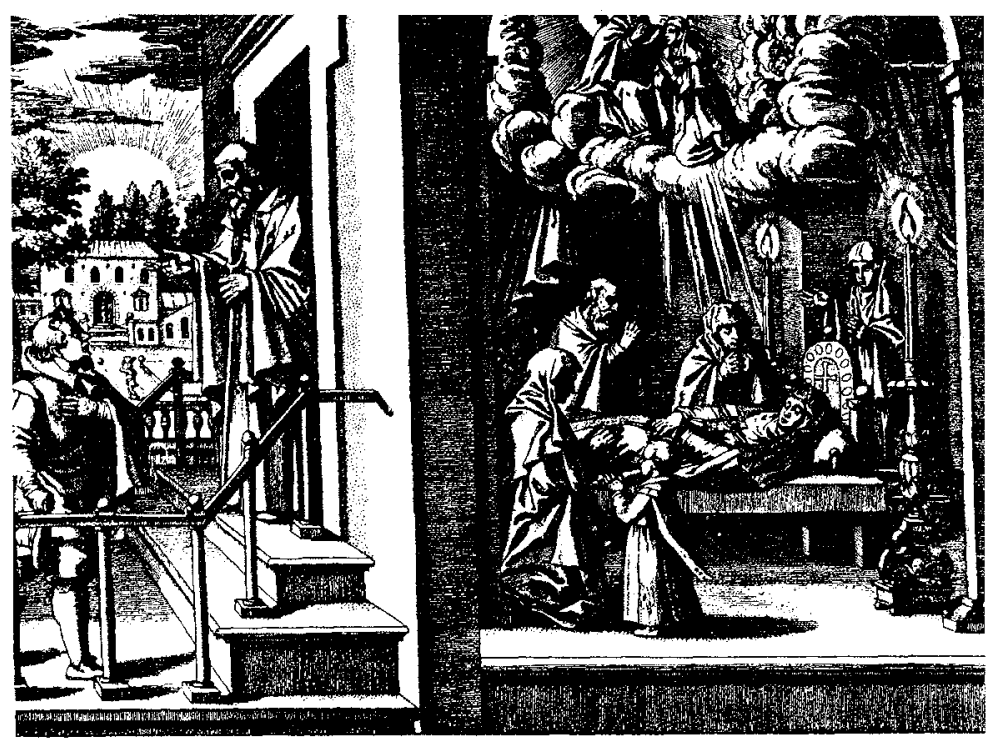

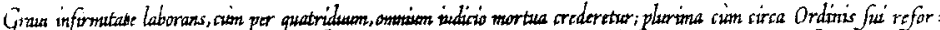

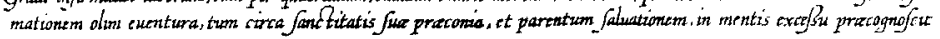

Fig. 7. Collaert, «Paroxismo de Santa Teresa, grabado número $\mathrm{V}$.

Como resumen de los expuesto, podemos subrayar la gran importancia de la serie completa a juzgar por los valores de los lienzos localizados. Abrigamos la ilusión de encontrarlos en sucesivas investigaciones.

\section{REPRESENTACIÓN DE SAN ISIDRO, PATRONO DE MADRID}

A continuación estudiaremos varias obras de Juan García de Miranda para diversas iglesias o ermitas madrileñas. Son escasos los datos que poseemos de varias de ellas, lo que dificulta la posible identificación del edificio o emplazamiento al que estuvieron destinadas. Sin embargo, cuando ello sea factible, procederemos a su localización o expresaremos nuestras hipótesis de donde pudieron estar ubicadas, basadas siempre en investigaciones serias y profundas aportando los diversos indicios que las puedan avalar. Tampoco debemos olvidar que el género religioso era considerado unánimente el más noble, más digno y significativo, pues, como afirma Pacheco, su fin era persuadir a los hombres a la piedad y llevarlos a Dios. El primer lienzo del que nos vamos a ocupar corresponde precisamente a la representación de San Isidro, patrono de Madrid. 


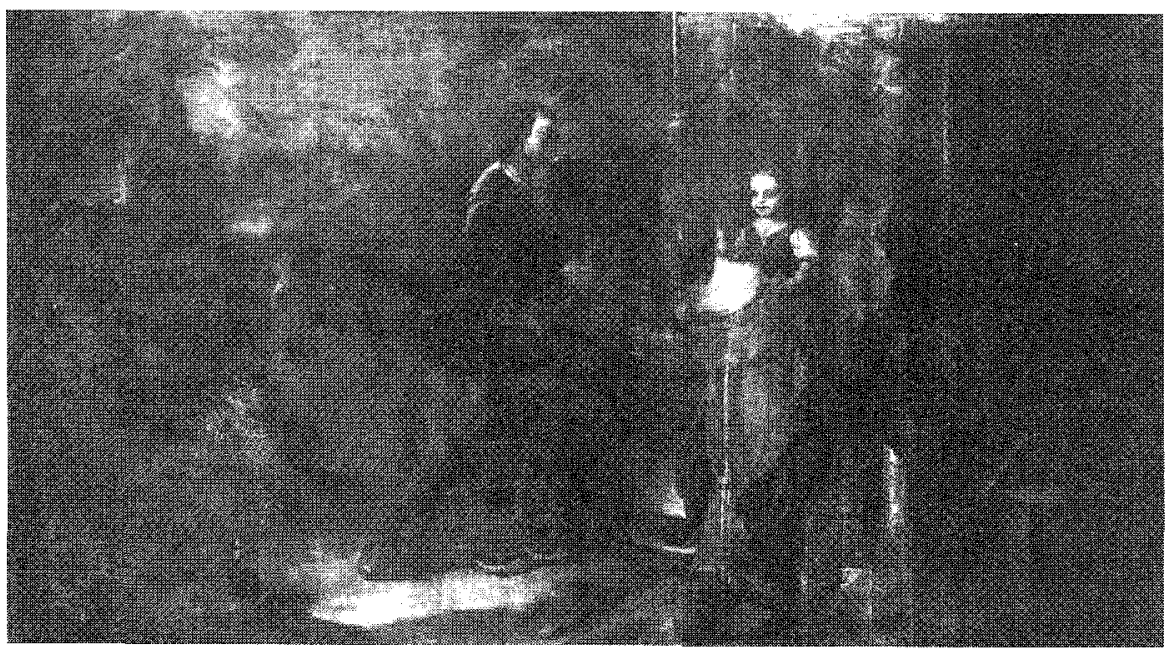

Fig. 8. Juan Garcia Miranda, "San Isidro y el milagro del pozo», Museo del Prado.

Este cuadro (fig. 8) ha sido uno de los que más problemática ha presentado en cuanto a su iconografía En el inventario manuscrito del Museo de la Trinidad aparecía incluido dentro de la serie de San Diego, describiéndose de la siguiente forma: «Asunto de la vida de Sn. Diego donde se ve al Sto. sacando á una niña de un pozo y una muger qe. la recibe en los brazos; figs. como de a vara y cuerpo entero». La misma atribución se mantiene en el catálogo impreso de Cruzada ${ }^{54}$, en Gaya Nuño ${ }^{55}$, y persiste incluso en el último inventario de pinturas del Museo del Prado ${ }^{56}$ donde se le denomina San Diego de Alcalá obrando el milagro del pozo. Carlos Trujillo García, en su artículo dedicado a Juan García de Miranda ${ }^{57}$, insiste que en el santo representado es San Diego e incluso afirma que el cuadro formó parte de la serie que decoró el claustro del convento de San Diego de Alcalá, describiendo la representación del lienzo como «Un niño es sacado del fondo de un pozo por la intercesión de San Diego, siendo abrazado por su madre, mientras un joven con cara de asombro tira de la cuerda. Sirve de fondo un bello paisaje con una arquitectura y un personaje femenino que se aleja por un camino".

\footnotetext{
54 Cruzada Villaamil, Gregorio, op. cit., pág. 84, núm. 498.

55 GaYa Nuño, Juan Antonio, op. cit., 1947, pág. 46, núm. 498.

56 MUSEO del Prado. Inventario General de Pintura. T. II. Museo de la Trinidad, op. cit., pág. 164, núm, actualizado 3.881 .

57 Trujlllo García, Carlos, op. cit., págs. 20-21.
} 
Nosotros, después de numerosas investigaciones y consultas de vidas de santos así como de estudios iconográficos, hemos llegado a la conclusión de que el santo representado es San Isidro y no San Diego, por las razones que expondremos a continuación.

En primer, lugar aunque es cierto que las medidas del lienzo $(111 \mathrm{x}$ $194 \mathrm{~cm}$ ) coinciden con las que presentan los restantes cuadros de la serie de San Diego del convento alcalaíno, no es razón suficiente para basar en ella la identificación temática y atribuírselo a este santo. Si contemplamos el conjunto de la serie vemos que en todos ellos la figura del santo aparece representada de manera bien visible con su hábito franciscano o su presencia se hace evidente a través de alguna imagen de su persona $o$ por medio de la aparición de su espíritu, manifestaciones que en este lienzo que nos ocupa están ausentes.

En segundo lugar en las diversas obras de la vida de San Diego no hemos encontrado narrado ningún episodio que pudiera coincidir $u$ ofrecer paralelismo con la escena aquí representada. E ello debemos añadir un nuevo interrogante si la figura del santo no aparece efigiada ¿qué símbolo o elemento del cuadro nos indica la intervención divina y que ésta sea precisamente la de San Diego y no la de cualquier otro santo?. Después de hacernos estas preguntas y de diversas búsquedas sólo hemos encontrado un santo en cuya vida se na re un episodio o milagro relacionado con el pozo que ofreciese similitudes y coincidencias con el representado por Juan García de Miranda y éste es precisamente San Isidro.

San Isidro es un santo medieval (1080?-1130) de dudosa historicidad. Desde joven se dedicó al trabajo del campo en el que transcurrió toda su vida. Se casó con la que posteriormente sería canonizada como Santa María de la Cabeza, siendo padres de un único hijo. Las escenas más representadas en obras artísticas corresponden a cuando los ángeles le suplen en el manejo del arado mientras él ora, el milagro de hacer brotar fuentes con el basión o bien orando. El episodio elegido en este lienzo corresponde al milagro del pozo que nos es narrado con detalle por Rivadeneyra ${ }^{58}$ y Quintana ${ }^{59}$. El hecho acontece mientras él estaba

58 Rivadeneyra, Pedro de, Flos Sanctorum, Madrid, 1761, págs. 89-98.

59 Quintana, Jerónimo de, Historia de la antigüedad, nobleza y grandeza de Madrid, Madrid, 1629 , págs. 130 y ss.; otros autores que relatan la vida de San Isidro son: DiAcono, Juan, Vita $S$. Isidori, Madrid, 1261; BLEDA, Jaime, Vida y milagros del glorioso San Isidro el Labrador, hijo, abogado y patrono de la real villa de Madrid, Madrid, 1622; Lope DE VEGA. Félix, La niñez de San Isidro, La juventud de San Isidro, San Isidro, labrador de Madrid, Madrid, 1622, edic. de Federico Sainz de Robles, Madrid, Aguilar, 1974; GARcíA VILLADA, Zacarías, "San Isidro Labrador en la historia y la literałura", Razón y fe, enero-mayo, 1922; FERRANDO RolG, , Juan, op. cit., págs. 142-143; 
trabajando en el campo, a cuyo regreso encuentra a su esposa muy afligida y llorosa, arrodillada ante el pozo. Al indagar la causa conoce que su hijo se ha ahogado en él. Se une a la oración de su esposa invocando la salvación del pequeño, y, sorprendentemente, ante sus ojos las aguas ascienden con el niño suspendido en su superficie. El santo ayuda a ello tirando de la cuerda de la garrucha del pozo. La madre emocionada y gozosa acoge al niño entre sus brazos. Este milagro alude al poder de la oración y la fé en la Divina Providencia.

El lienzo ilustra perfectamente esta escena y responde a la iconografía usual con la que suele representarse a San Isidro. Va vestido con chaqueta y calzón corto, propio de los labriegos de Castilla; su sombrero yace en el suelo al pie del pozo. Una serie de elementos contribuyen a identificar al santo, como son el pozo y el azadón. La figura del santo ocupa el eje vertical central de la composición, creando una sensación de movimiento al disponerse sus extremidades en aspa, que queda enmarcada entre verticales a izquierda y derecha. A la derecha, bien visible, se sitúa el pozo. Junto a él la madre, de espaldas, semiarrodillada se alza para acoger en sus brazos al niño, que muestra un semblante apacible y sereno, convirtiéndose casi en el protagonista de la escena, subrayado con una mayor iluminación. Compensando masas, el lateral izquierdo del lienzo aparece ocupado por una visión de un paisaje en perspectiva, cuyo árbol constituye el cierre del cuadro y en dicho paisaje se inserta una construcción rematada en chapitel, presumiblemente una ermita, que evoca las arquitecturas madrileñas de la época de los Austrias, tan representadas en las vistas velazqueñas y de Martínez Mazo, entre otros. Se aprecia, aunque no muy claramente por el estado de conservación del cuadro, la silueta de una figura que camina en medio de la vegetación hacia la ermita para dar gracias por el milagro.

Toda la escena, hasta en sus pormenores, está resuelta con toda una gradación de colores calientes, pasando del rojo al dorado, unidos a los verdes azules y verdes intensos, logrando en cada elemento su calidad y tonalidad propia. El color rojizo carminoso del vestido de Santa María de la

\footnotetext{
RÉAu, Louis, L'lconographie de l'art chrétien. París, 1955-1959, t. Ill, II, págs. 688-689; BALtar, Salvador, "San Isidro", Año cristiano, Madrid, 1959, t. II, págs. 375-380; FERNÁndez ALonso, Justo y CELLETTI, Chiara, Bibliotheca Sanctorum, Roma, 1964, t. VII, págs. 953-957; RAMOS, M., “Isidro Labrador», en Aldea Vaquero, Quintín, MARín MARTínez, Tomás y Vives GATell, José, Diccionario de historia eclesiástica de España. Madrid, 1973-1975, t. II, págs. 12-14; Revilla, Federico, Diccionario de iconografía. Madrid, 1990, pág. 199; ORIHUELA MAESO, Mercedes, "Iconografía de San Isidro y Santa María de la Cabeza", Revista de la Biblioteca, Archivo y Museo del Ayuntamiento de Madrid, 1980, núm. 6, págs. 27-45.
} 
Cabeza se acompasa con el blanco de la camisa del niño, que asoma bajo el corpiño de tonalidad marrón-terrosa y cubre su cuerpecito. El escote de la madre y la ingenuidad del niño presentan un cierto italianismo, similar al que refleja la versión de Alonso Cano del Museo del Prado.

La iluminación incide sobre las figuras y detalles principales de la escena: Santa María y el niño, la figura del Santo, el camino que conduce a la ermita, los arreboles celeste que evocan la intervención celestial. La luz constituye también un elemento esencial para la creación del espacio ambiental. Los efectos de profundidad y perspectiva están bien logrados a través de los focos luminosos del sendero y del cielo que nos ilumina la ermita, aproximándola a un plano más cercano. Las figuras, la profundidad del arbolado y otros elementos nos van marcando los distintos planos de proximidad y lejanía.

Es un cuadro eminentemente histórico y realista, en el que no falta los atributos que caracterizan al santo y la escena, y en el, que dado su carácter narrativo, no predominan las alusiones alegóricas o simbólicas. En cambio si existe una alusión al tiempo en la simultaneidad de las dos escenas: la salvación del niño y la posterior de dirigirse a la ermita para dar gracias a Dios.

Esta misma escena fue representada por Alonso Cano (fig. 9) en su cuadro del Museo del Prado ${ }^{60}$, ofreciendo, junto con el de Miranda, la peculiaridad señalada por Revilla ${ }^{61}$ de haber dejado el azadón representativo del trabajo de labrador, pero permaneciendo bien visible. Otra representación es la también conservada en el Museo del Prado como anónimo madrileño del siglo XVII ${ }^{62}$, a ésta se suman la de Atanasio Bocanegra en el Museo de Santa Cruz de Toledo, las dos representaciones correspondientes a la iglesia de San Andrés, donde se encontraba un cuadro de Rizi, fechado entre 1663 y 1668, hoy desaparecido, que decoraba con este milagro la cúpula dedicada al santo en la capilla de su nombre, la otra representación corresponde a un pequeño relieve. También se conserva otro lienzo, con este tema, obra de un anónimo del XVII, en la colección Arenaza, pintando al niño sentado en el brocal, rodeado de San Isidro, Santa María de la Cabeza, arrodillada, otra mujer y diversos niños. Otra pintura, inspirada en este milagro, es la del Museo Municipal de

60 MUSEO DEL PRADO. Catálogo de pinturas, Madrid, 1972, pág. 114, núm. 2806, Alonso Cano, El milagro del pozo, $216 \times 149 \mathrm{~cm}$.

61 ReVILLA, Federico, op. cit,, 1990, pág. 199.

62 MUSEO DEL PRADO. Inventario General de Pinturas. T. II. El Museo de la Trinidad, op. cit., 1991, pág. 231, núm. inv. 3.367, $163 \times 107 \mathrm{~cm}$. 


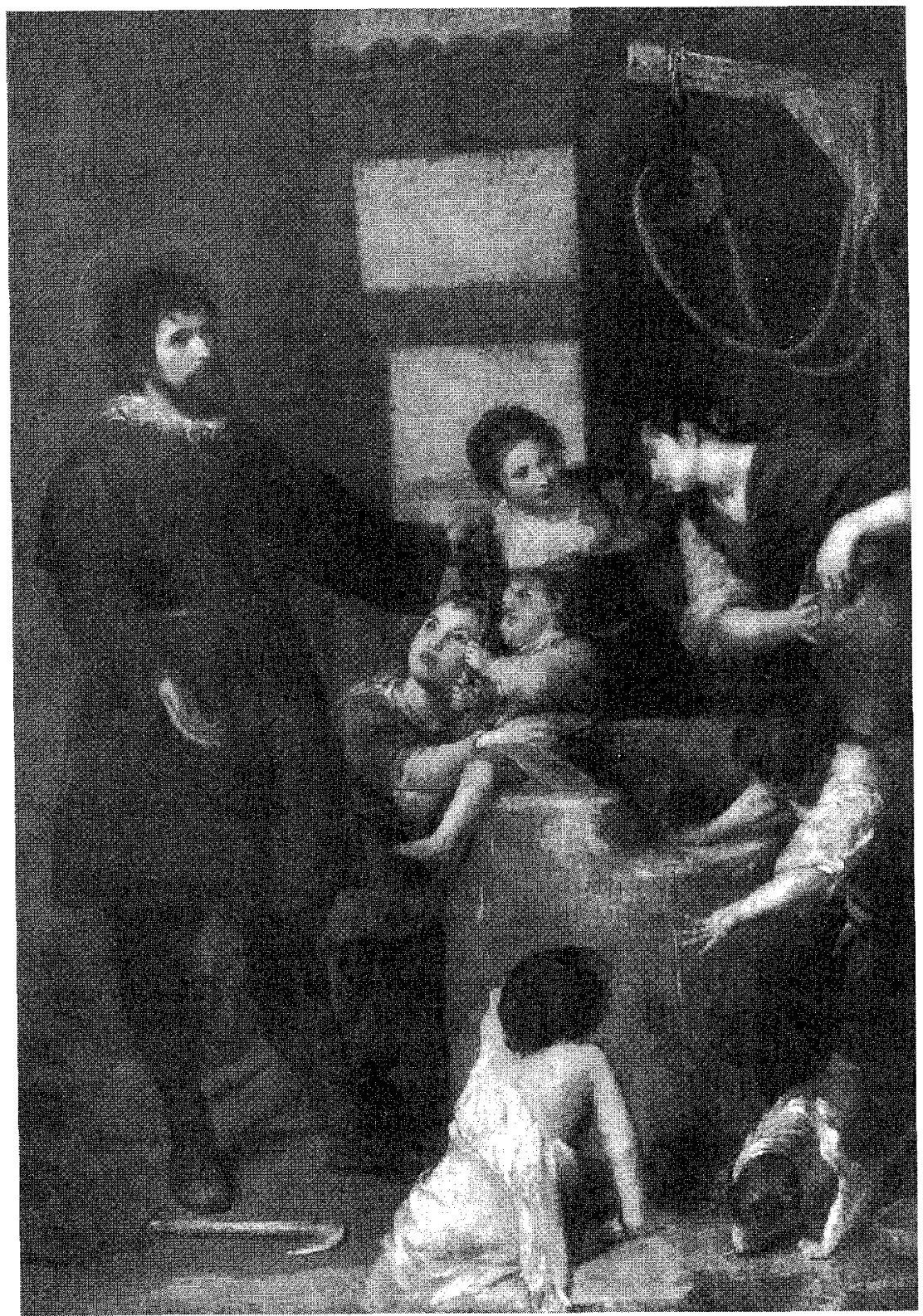

Fig. 9. Alonso Cano, «El milagro del pozo». Museo del Prado. 
Madrid (fig. 10), al igual que la anterior anónima. Interesante y curioso es el grabado ${ }^{63}$, a modo de «aleluyas», que presenta dieciocho recuadros con otras tantas escenas de la vida de San Isidro, correspondiendo la decimoquinta al milagro del pozo. Otra representación escultórica del Santo, rescatando a su hijo de las aguas del pozo, se encuentra en el madrileño Puente de Toledo. En el momento de su canonización en 1622 se editó un

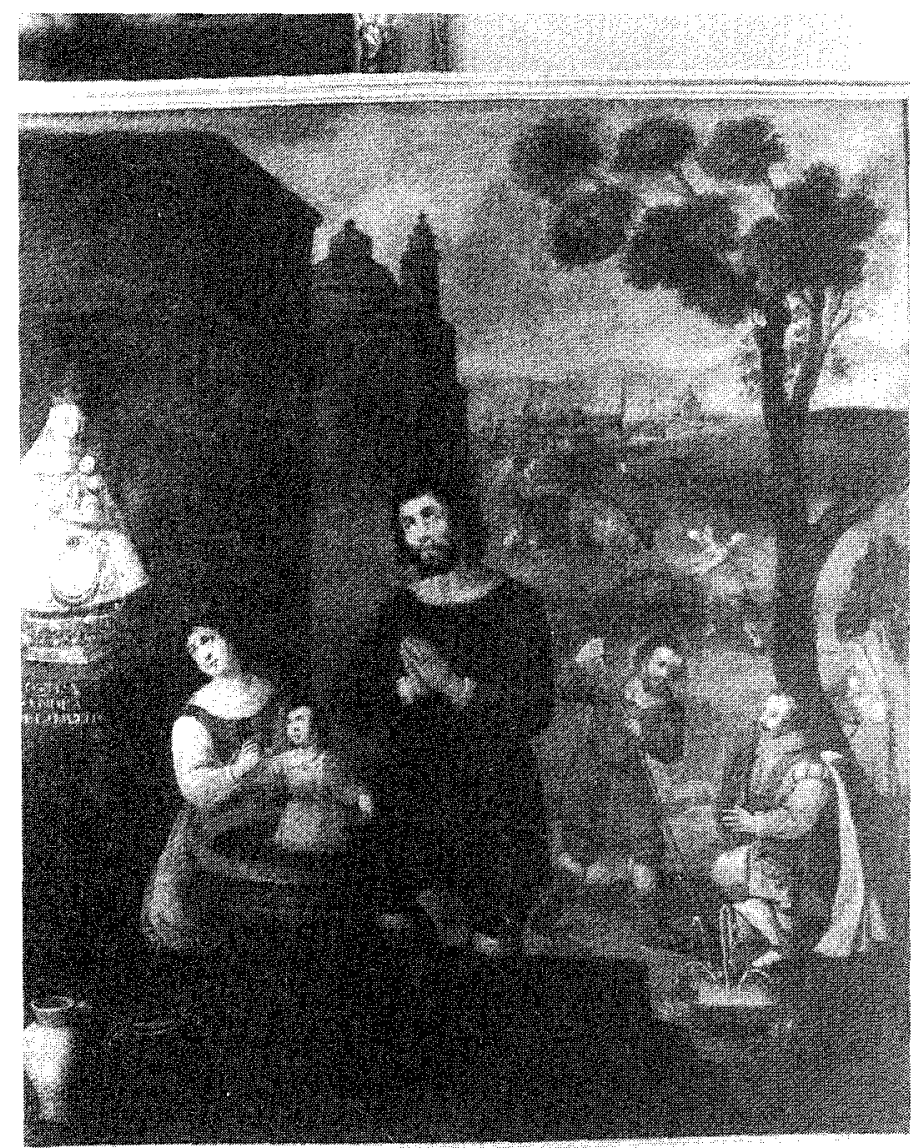

Fig. 10. Anónimo. S. XVII-XVIII. Madrid: Museo Municipal.

63 Museo Municipal de Madrid, grabado en cobre, talla dulce (311 x $205 \mathrm{~mm})$, IN 2436, 2437, 2438 (iluminado), 4851, 4852 y 20184. Reproducido en GARRETE PARRondo, Juan, Diego, Estrella 
grabado según Ch. Clair ${ }^{64}$, en que junto a la fiesta de la canonización a los lados se representan los cuatro santos canonizados ese mismo día, siendo uno de ellos San Isidro. Todos aparecen orlados con pequeños grabados alusivos a momentos significativos de su vida (fig. 11).

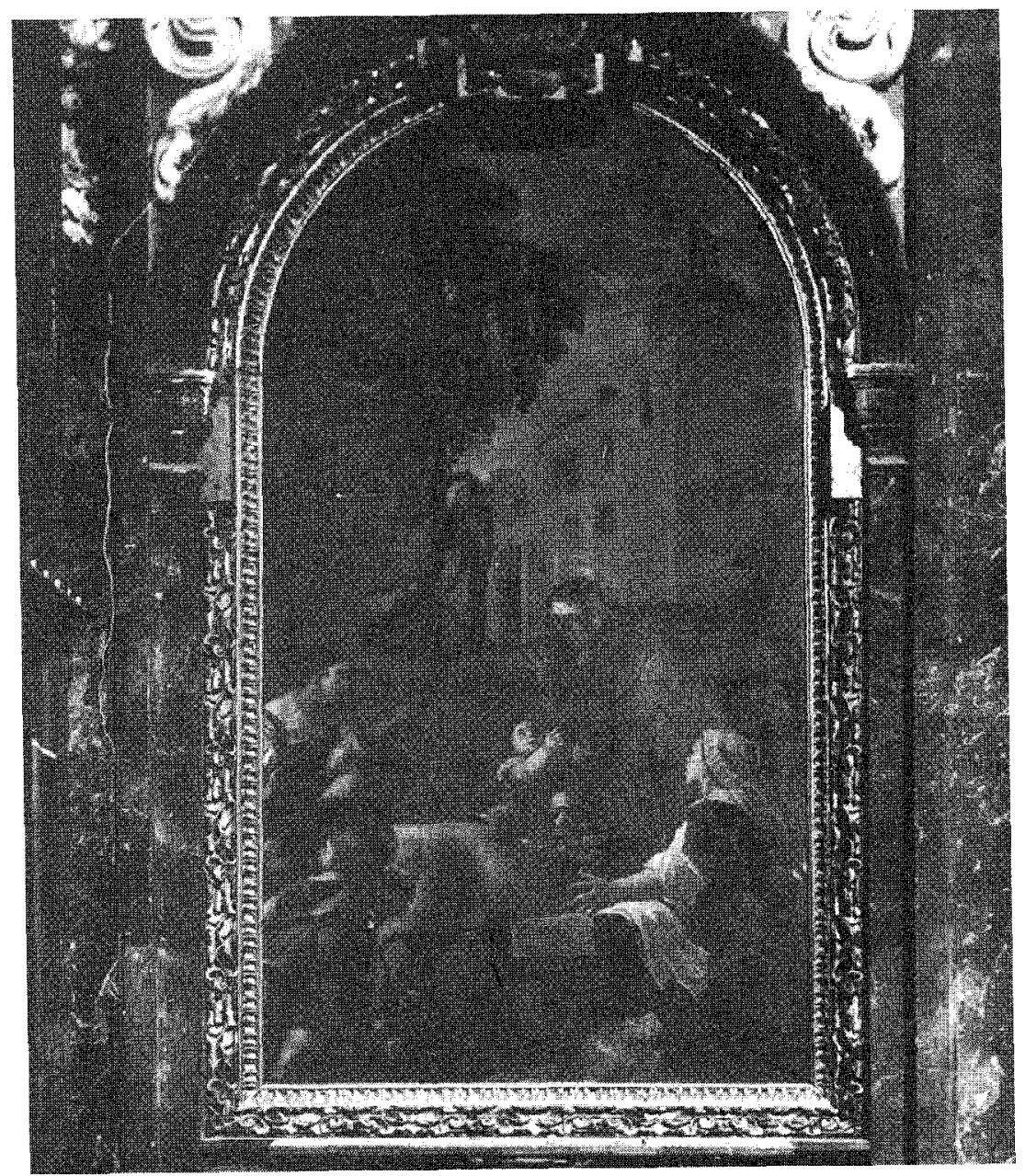

Fig. 11. Anónimo español. Archivo Moreno.

de y VEGA, Jesusa, Catálogo del Gabinete de Estampas del Museo Municipal de Madrid. Estampas españolas. Grabado, 1550-1820, 2 vols., Madrid, 1985, pág. 598 (cat. núm. 331).

64 MALE, Émile, El Barroco. Madrid, 1985, pág. 107-108. 
San Isidro fue proclamado patrón de Madrid, ciudad en la que precisamente transcurre la vida de Juan García de Miranda. También sabemos que este artista trabajó en la ermita del santo donde pintó una Virgen de la Porteria, y pudiera ser que esta obra hubiese sido realizada para dicha ermita, de la que era patrón, o bien para otra iglesia o convento madrileño.

La fecha de realización del lienzo, por su estilo artístico, debe situarse próxima a la de la serie de San Diego de Alcalá.

Los milagros del Santo inspiraron también diversas obras y composiciones literarias como las de Lope de Vega tituladas La niñez de San Isidro, La juventud de San Isidro, San Isidro Labrador de Madrid. 